\title{
Biologic canine and human intervertebral disc repair by notochordal cell-derived matrix: from bench towards bedside
}

\author{
Frances C. Bach ${ }^{1}$, Anna R. Tellegen ${ }^{1}$, Martijn Beukers ${ }^{1}$, Alberto Miranda-Bedate ${ }^{1}$, \\ Michelle Teunissen ${ }^{1}$, Willem A.M. de Jong $^{1}$, Stefan A.H. de Vries ${ }^{2}$, Laura B. \\ Creemers $^{3}$, Karin Benz ${ }^{4}$, Björn P. Meij ${ }^{1}$, Keita Ito ${ }^{2,3}$ and Marianna A. Tryfonidou ${ }^{1}$ \\ ${ }^{1}$ Department of Clinical Sciences of Companion Animals, Faculty of Veterinary Medicine, Utrecht University, Utrecht, 3584 \\ $\mathrm{CM}$, The Netherlands \\ ${ }^{2}$ Orthopaedic Biomechanics, Department of Biomedical Engineering, Eindhoven University of Technology, Eindhoven, MB \\ 5600, The Netherlands \\ ${ }^{3}$ Department of Orthopedics, University Medical Centre Utrecht, Utrecht, 3584 CX, The Netherlands \\ ${ }^{4}$ TETEC AG, Reutlingen 72770, Germany \\ Correspondence to: Marianna A. Tryfonidou, email: m.a.tryfonidou@uu.nl \\ Keywords: intervertebral disc; regenerative medicine; notochordal cells; canine; human
}

Received: March 13, $2018 \quad$ Accepted: April 28, $2018 \quad$ Published: May 29, 2018

Copyright: Bach et al. This is an open-access article distributed under the terms of the Creative Commons Attribution License 3.0 (CC BY 3.0), which permits unrestricted use, distribution, and reproduction in any medium, provided the original author and source are credited.

\section{ABSTRACT}

The socioeconomic burden of chronic back pain related to intervertebral disc (IVD) disease is high and current treatments are only symptomatic. Minimally invasive strategies that promote biological IVD repair should address this unmet need. Notochordal cells (NCs) are replaced by chondrocyte-like cells (CLCs) during IVD maturation and degeneration. The regenerative potential of NC-secreted substances on CLCs and mesenchymal stromal cells (MSCs) has already been demonstrated. However, identification of these substances remains elusive. Innovatively, this study exploits the regenerative NC potential by using healthy porcine NC-derived matrix (NCM) and employs the dog as a clinically relevant translational model. NCM increased the glycosaminoglycan and DNA content of human and canine CLC aggregates and facilitated chondrogenic differentiation of canine MSCs in vitro. Based on these results, NCM, MSCs and NCM+MSCs were injected in mildly (spontaneously) and moderately (induced) degenerated canine IVDs in vivo and, after six months of treatment, were analyzed. NCM injected in moderately (induced) degenerated canine IVDs exerted beneficial effects at the macroscopic and MRI level, induced collagen type II-rich extracellular matrix production, improved the disc height, and ameliorated local inflammation. MSCs exerted no (additive) effects. In conclusion, NCM induced in vivo regenerative effects on degenerated canine IVDs. NCM may, comparable to demineralized bone matrix in bone regeneration, serve as 'instructive matrix', by locally releasing growth factors and facilitating tissue repair. Therefore, intradiscal NCM injection could be a promising regenerative treatment for IVD disease, circumventing the cumbersome identification of bioactive NC-secreted substances.

\section{INTRODUCTION}

Over $80 \%$ of the human population experiences low back pain (LBP) at least once in their life, with severe socioeconomic consequences [1]. Degeneration of the intervertebral disc (IVD) is a common cause of chronic LBP [2]. Current treatments for LBP due to IVD degeneration mainly aim at symptom reduction or IVD 
replacement and are not without their inherent limitations. Therefore, LBP should be addressed at an earlier stage by minimally invasive strategies that induce definitive longterm biological IVD repair.

The IVD transmits loads and provides flexibility to the spine. The healthy IVD consists of a gelatinous nucleus pulposus (NP), surrounded by a fibrous annulus fibrosus (AF) and cartilaginous end plates (EPs). During IVD degeneration, the glycosaminoglycan (GAG) content of the NP decreases and collagen type II is replaced by collagen type I, resulting in a more rigid NP tissue that is not able to sustain compressive loads anymore. Since the IVD cannot adequately repair its matrix, the IVD weakens and is further damaged by physiologic loading [3]. During IVD maturation in humans, a transition in NP cell phenotype takes place from large, vacuolated notochordal cells (NCs) to smaller, non-vacuolated chondrocyte-like cells (CLCs) [4]. NC loss in certain species (e.g. chondrodystrophic dogs) coincides with the onset of degenerative IVD changes [3]. Moreover, the regenerative potential of NCs has already been demonstrated on CLCs [5-7], mesenchymal stromal cells (MSCs) [8-10], and NP tissue explants [11] in vitro, and in rat IVDs in vivo [12]. Altogether, this indicates that NCs can play a role in maintaining healthy NP tissue. Therefore, NCs are a promising target for regenerative and/or symptom modifying therapies for IVD disease.

Despite the current focus on the NC secretome [12-14], we here take an innovative approach, by using the entire NC-derived matrix (NCM) from healthy NCrich NP tissue, as a first step towards clinical translation. NCM may act rather comparable to demineralized bone matrix (DBM), derived from bovine or human donors (e.g. Bio-Oss ${ }^{\circledR}, \mathrm{DBX}^{\circledR}$ ). DMB is known to contain ECM and growth factor components native to bone and is currently successfully employed in clinical practice to accelerate bone healing [15]. Therefore, the first aim of this study was to determine the (regenerative) effects of NCM on CLCs from degenerated IVDs in vitro and injected NCM in degenerated IVDs in vivo. For this purpose, we employed porcine NCM given that we have previously shown that porcine NCs exert the strongest anabolic effects on CLCs derived from human and canine degenerated IVDs over human and canine NCs [5]. Since cell viability is impaired in the degenerated IVD [16], NCM alone may not be sufficient. In this respect, intradiscal MSC transplantation is considered a promising regeneration strategy, currently explored in clinical trials (NCT01290367, NCT02412735) [17]. Therefore, the second aim of this study was to determine the effects of NCM combined with MSCs on degenerated canine IVDs in vivo. The dog served herein as a translational model, since they experience LBP due to IVD degeneration with similar characteristics as humans [18].

\section{RESULTS}

\section{NCM increased DNA content, GAG and collagen deposition in CLC micro-aggregates in vitro}

In the current study, $10 \mathrm{ng} / \mathrm{mL}$ TGF- $\beta_{1}$ was used as positive control to demonstrate the chondrogenic capacity of the donors employed, and indeed increased the DNA and GAG content of the micro-aggregates and induced proteoglycan synthesis in human and canine CLCs $(p<$ 0.05 , Figure $1 \mathrm{~A}-1 \mathrm{H})$. NCM increased the DNA, GAG, and GAG/DNA content of canine and human CLC micro-aggregates after 28 days of culture $(p<0.05$, Figures $1 \mathrm{~A}-1 \mathrm{~F}$ and 2 ); the cells demonstrated a typical chondrocyte-like appearance. Given that NCM is rich in ECM components, we explored whether CLCs produced and/or incorporated the matrix provided during culture. The ${ }^{35} \mathrm{SO}_{4}{ }^{2-}$ incorporation assay demonstrated that NCMtreated human CLCs synthesized less proteoglycans than controls $(p<0.001$; Figure $1 \mathrm{H})$, which may indicate that GAGs were incorporated in the micro-aggregates from NCM, instead of being synthesized by the human CLCs. In contrast, NCM induced proteoglycan synthesis in canine CLCs $(p<0.01$, Figure $1 \mathrm{G})$, indicating that they (also) synthesized GAGs themselves. Collagen type I and II deposition appeared increased in 28-day NCMtreated CLC micro-aggregates whereas collagen type $\mathrm{X}$ (hypertrophy marker) was not observed (Figure 2). Altogether, NCM induced GAG and collagen type II-rich matrix deposition in CLCs in vitro.

\section{NCM supports MSC chondrogenesis in vitro}

The effect of NCM was tested on MSCs from three canine donors. Positive control treatment (TGF- $\left.\beta_{1}\right)$ increased the GAG and GAG/DNA content of MSC micro-aggregates versus controls $(p<0.05$, Figure 3B-3D), indicating successful chondrogenic differentiation. The DNA and GAG content of NCM-treated microaggregates was higher versus TGF- $\beta_{1}$-treated microaggregates $(p<0.05$, Figure $3 \mathrm{~A}-3 \mathrm{~B})$. The GAG/DNA content of micro-aggregates treated with TGF- $\beta_{1}$ or NCM was increased versus controls $(p<0.05)$, with no differences between conditions (Figure $3 \mathrm{C}$ ). Additionally, both TGF- $\beta_{1}$ and NCM induced collagen type I and II deposition, whereas collagen type $\mathrm{X}$ was not deposited (Figure 3D). Lastly, NCM-treated micro-aggregates contained phenotypically chondrocyte-like cells, surrounded by collagen type II and GAG/rich extracellular matrix (Figure 3D). Altogether, NCM supported chondrogenesis of canine MSCs in vitro.

\section{MSC characterization}

To demonstrate that bone marrow-derived stromal cells from the male Beagle donor injected in the female 
A

Canine

\section{DNA content}

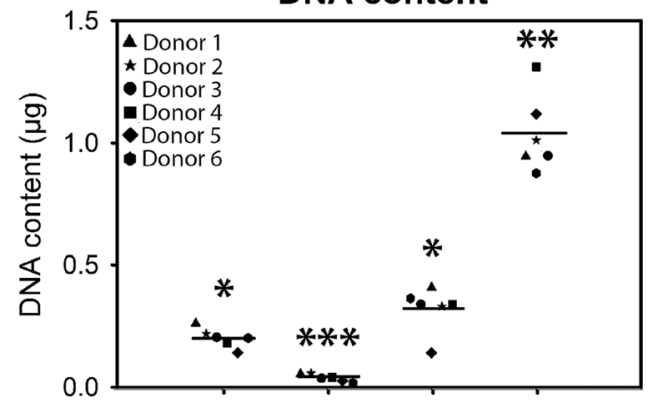

Day 0 Control TGF-ß NCM

C

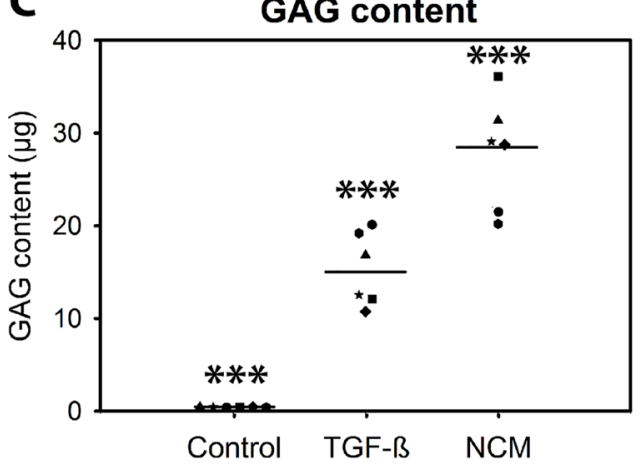

E

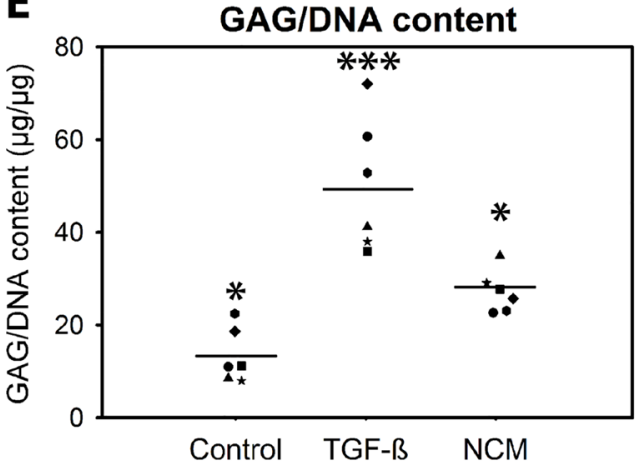

$\mathbf{G}$

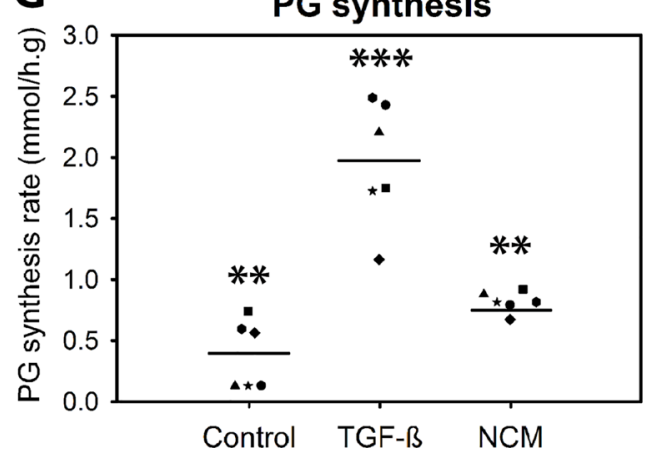

B

Human

DNA content

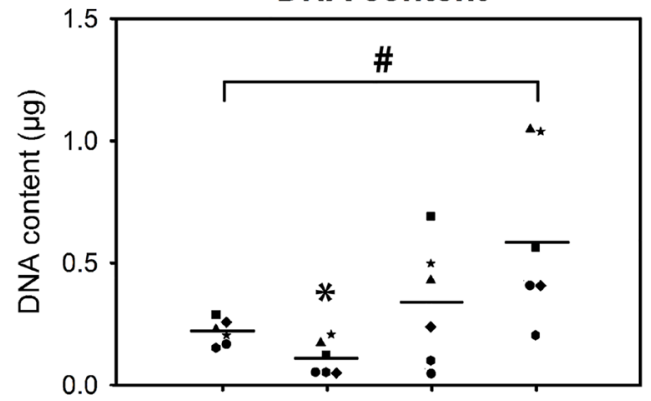

Day 0 Control TGF- $\beta$ NCM

D

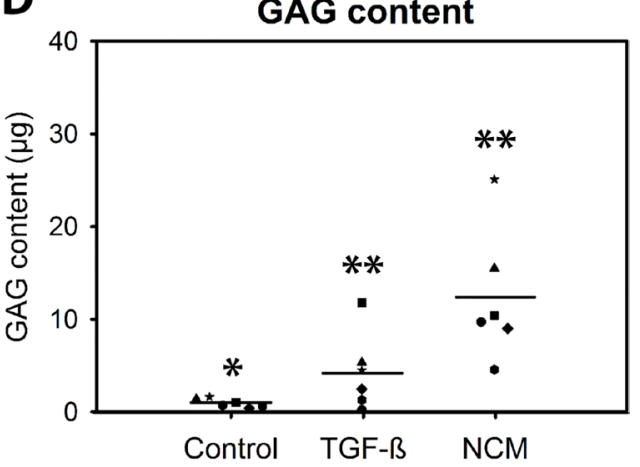

$\mathbf{F}$

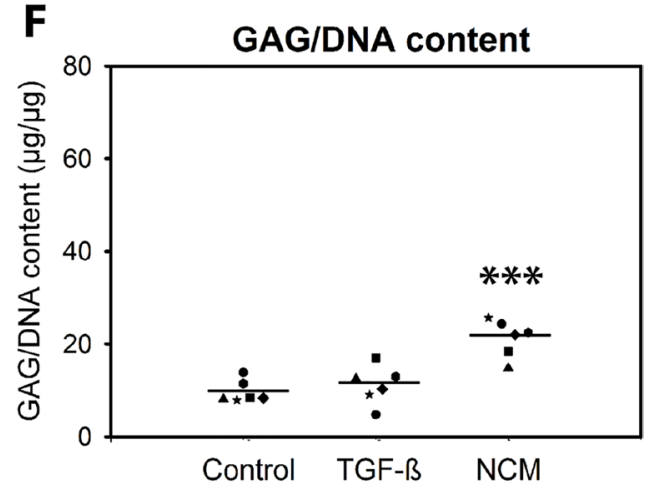

H

PG synthesis

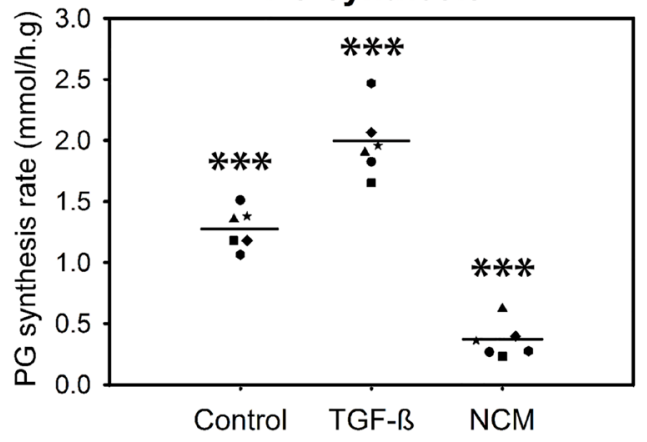

Figure 1: Notochordal cell-derived matrix (NCM) increases the DNA (A, B), glycosaminoglycan (GAG; C, D) and GAG/DNA (E, F) content of chondrocyte-like cell (CLC) micro-aggregates. Average of two samples per donor with depicted mean values. CLC microaggregates of 35,000 cells were cultured in basal culture medium (negative control), supplemented with $10 \mathrm{ng} / \mathrm{mL}$ TGF- $\beta_{1}$ (positive control), or $10 \mathrm{mg} / \mathrm{mL} \mathrm{NCM}$ for 28 days. ${ }^{35} \mathrm{SO}_{4}{ }^{2-}$ incorporation (proteoglycan (PG) synthesis rate) was determined at day $7(\mathbf{G}, \mathbf{H}) .{ }^{* * * * * * *} p<0.05$, $p<0.01$, and $p<0.001$, respectively, for the indicated condition versus all other conditions; ${ }^{*} p<0.05$ for the two indicated conditions by the horizontal bar; $n=6$ per species, in duplicates. ANOVA (normally distributed data), Kruskal Wallis/Mann-Whitney U (non-parametric data), and Benjamini \& Hochberg tests were performed. 
Beagle IVDs met requirements to be defined as MSCs, multilineage differentiation and FACS analysis was performed [19]. Chondrogenic, osteogenic, and adipogenic differentiation were successfully induced, and cells were $\mathrm{CD}^{-} 4^{-}, \mathrm{CD}^{-} 5^{-}, \mathrm{CD} 29^{+}$and CD90 ${ }^{+}$(Supplementary File 1). Only $4.4 \%$ of cells were $C D 105^{+}$, possibly explained by low cross-species reactivity of anti-human CD105 used due to unavailability of commercial anti-canine CD105 [20]. Altogether, the results confirmed the presence of MSCs in the intradiscally injected cells.

\section{Induction of IVD degeneration in vivo}

To enable studying the effect of the treatments on mildly, and also on more severely degenerated IVDs, six weeks before the start of the experiment $(\mathrm{T}=-1.5$ months), moderate IVD degeneration was induced by partial NP removal (NX) in five IVDs per Beagle dog (NX-IVDs; $n=6$ dogs, Supplementary File 2A-2B). Six weeks later ( $T=0$ months), the noNX-IVDs (IVDs in which no NX was performed) and the NX-IVDs were either not injected (controls) or injected with $\mathrm{NCM}$, MSCs, or NCM+MSCs (Supplementary File $2 \mathrm{G}-2 \mathrm{H})$. At $\mathrm{T}=3$ months, two NCM-treated IVDs per dog received an additional NCM injection. One Beagle died unexpectedly at $\mathrm{T}=0$ (cause of death unrelated to treatment) and the IVDs of this dog were used as baseline values for moderate (induced) IVD degeneration $(n=1$ dog). At $\mathrm{T}=0$ months, the AF appeared not affected by the induction of moderate IVD degeneration (Supplementary File 2D, 2I-2M). In contrast, NPs of NX-IVDs showed macroscopically a brown discoloration (Supplementary File 2D), histologically less intense Alcian blue (GAG) and more intense Picrosirius Red (collagen) staining (Supplementary File 2E-2F), and biochemically a decreased GAG and GAG/DNA content $(p \leq 0.05$; Supplementary File 2I, 2K) in comparison with NPs of noNX-IVDs, indicating that degeneration was successfully modified from mild (spontaneous) to moderate (induced) IVD degeneration. Lastly, it was confirmed in two IVDs (Th12-13, NX and Th13-L1, noNX) of the female dog, which died immediately post-operatively due to unknown reasons, that injected male MSCs could be detected (SRY DNA), indicating proper intradiscal MSC injection and tracking (Supplementary File 2N).

\section{The effect of NCM on degenerated canine IVDs in vivo}

At $\mathrm{T}=6$ months, the effect of the different treatments (control, 1xNCM, NCM reinjection after three months (2xNCM), MSC, NCM+MSC) on mildly and
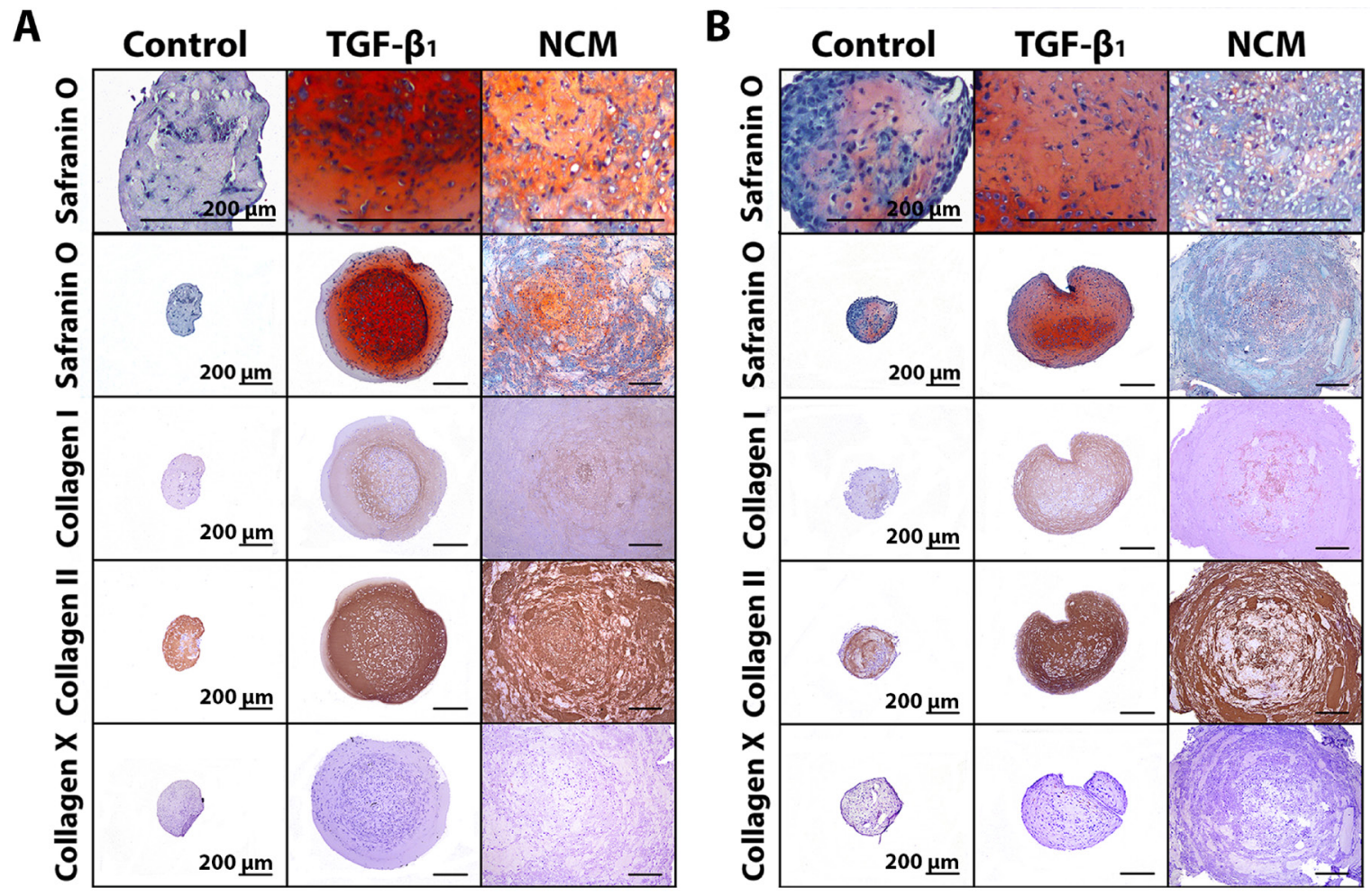

Figure 2: Notochordal cell-derived matrix (NCM) induces extracellular matrix deposition by chondrocyte-like cells (CLCs). Safranin O/Fast Green staining and collagen type I, II, and X immunohistochemistry of canine (A) and human (B) CLC microaggregates of 35,000 cells cultured in basal culture medium (negative control), supplemented with $10 \mathrm{ng} / \mathrm{mL}$ TGF- $\beta_{1}$ (positive control), and $10 \mathrm{mg} / \mathrm{mL} \mathrm{NCM}$ for 28 days. $n=6$ per species, in duplicates. All scale bars indicate $200 \mu \mathrm{m}$. 

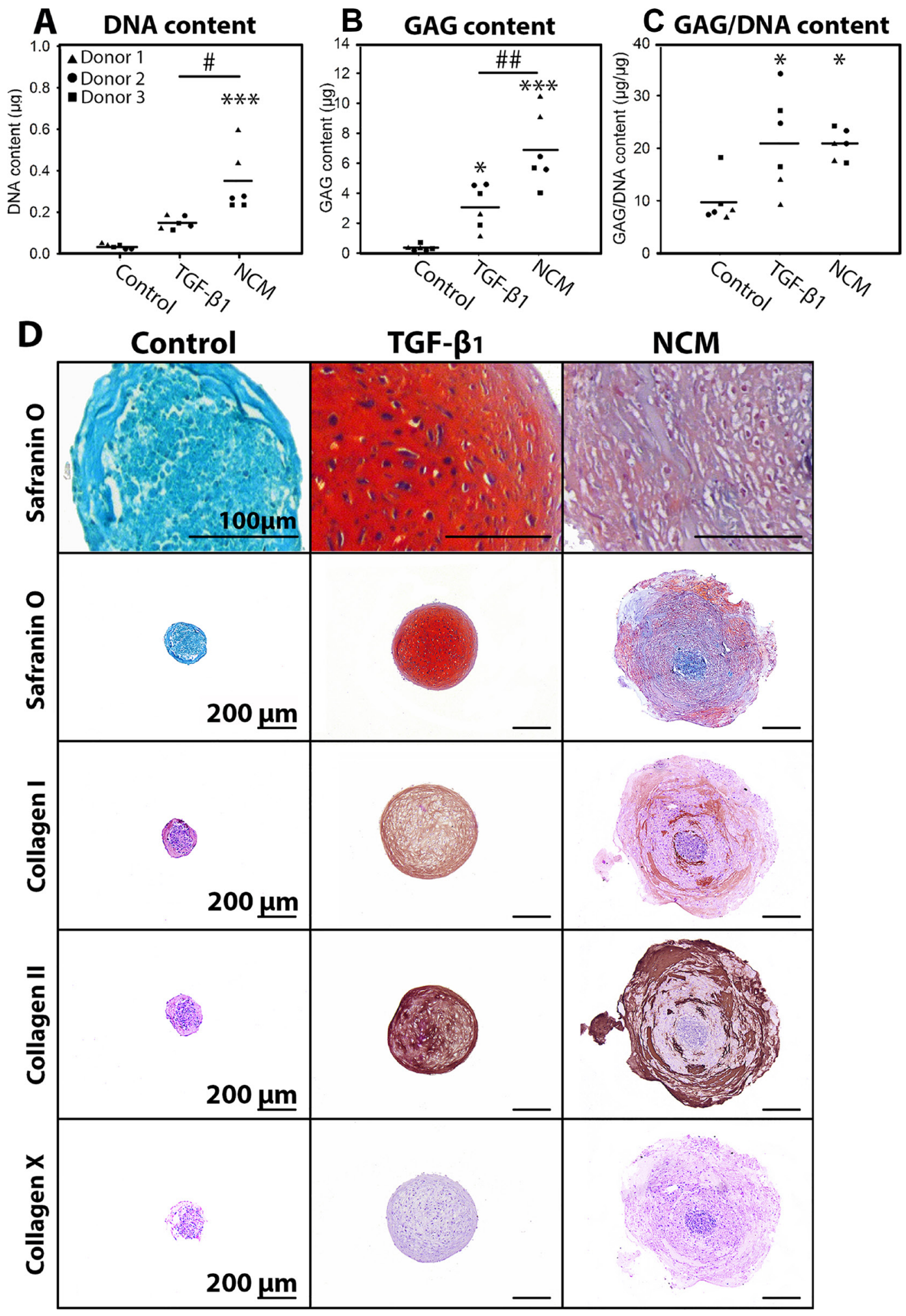

Figure 3: Notochordal cell-derived matrix (NCM) facilitates chondrogenic differentiation of canine MSCs. DNA (A), glycosaminoglycan (GAG; B) and GAG/DNA (C) content. MSC micro-aggregates of 35,000 cells were cultured in (negative) control culture medium, supplemented with $10 \mathrm{ng} / \mathrm{mL}$ TGF- $\beta_{1}$ (positive control) or $10 \mathrm{mg} / \mathrm{mL} \mathrm{NCM}$ for 28 days. (D) Safranin O/Fast Green staining and collagen type I, II, and X immunohistochemistry at day $28 .{ }^{* * * * *} p<0.05, p<0.001$, respectively, for the indicated condition versus controls; $\#, \# p<0.05$ and $p<0.01$, respectively, for the two indicated conditions by the horizontal bar; $n=3$ in duplicates; mean values are given. ANOVA (normally distributed data), Kruskal Wallis/Mann-Whitney U (non-parametric data), and Benjamini \& Hochberg tests were performed. 
moderately degenerated canine IVDs was determined using macroscopic, radiologic, histologic and biochemical analysis ( $n=5$ dogs). First, the IVDs were scored according to macroscopic Thompson (grade 1-5) [21] and MRI-based Pfirrmann (grade 1-5) [22] grading validated for dogs; grades increase with degeneration. At $\mathrm{T}=6$ months, control NX-IVDs had a higher median Thompson and Pfirmann score than control noNX-IVDs $(p=0.08$ with large effect size (ES) and $p<0.01$, respectively; Figure 4A-4B), indicating that more severe IVD degeneration was induced with NX. The Thompson and Pfirrmann score of noNX-IVDs did not improve by any treatment. In contrast, 2xNCM-treated NX-IVDs tended to show a lower median Thompson and Pfirrmann score than control NX-IVDs ( $p=0.08$ and 0.15 , large ES) and did not differ from control noNX-IVDs indicating reversal or halting of the degenerative process. In line with this, all NX-IVD NPs showed a brown discoloration (compatible with IVD degeneration), except 2xNCM-treated IVDs in four out of five dogs (Figure 4C). Altogether, 2xNCM improved the Thompson and Pfirrmann score of moderately degenerated IVDs.

The Disc Height Index (DHI) did not significantly change from $\mathrm{T}=0$ until $\mathrm{T}=6$ months in control-, $1 \mathrm{xNCM}-$, MSC- and NCM+MSC-treated noNX-IVDs, but tended to increase in time by $2 \mathrm{xNCM}(p=0.14$, large ES; Figure 4D). In control NX-IVDs, the DHI did not considerably change from $\mathrm{T}=0$ to $\mathrm{T}=6$ months. In $1 \times \mathrm{xNCM}-, 2 \mathrm{xNCM}-$ and $\mathrm{NCM}+\mathrm{MSC}$-treated, but not MSC-treated NX-IVDs, the increase in DHI tended to be higher versus control NXand noNX-IVDs $(p=0.06-0.09$, large ES), indicating a NCM specific effect.

T1 $\rho$ and T2 MRI values were employed for quantitative MRI analysis. T1 $\rho$ values did not significantly change in time, regardless the condition (mean: 0.59, SD: $0.14)$. $\mathrm{T} 2$ values were not different between $\mathrm{T}=0$ and $\mathrm{T}=6$ months in noNX-IVDs (Figure 4E). In all NX-IVDs, T2 values decreased in time versus control noNX-IVDs ( $p<0.05$, or $p=0.05-0.08$ with large ES). Altogether, induction of degeneration reduced $\mathrm{T} 2$ values, but no treatment was able to increase $\mathrm{T} 2$ values during the six months follow up period.

Lastly, the presence and progression of Modic Changes (MCs), periosteal bone formation, ventral spondylosis and EP lysis was recorded (Supplementary File 3). In noNX-IVDs, MCs or EP lysis were not induced by any of the treatments. Periosteal bone formation and mild ventral spondylosis was observed only in three 1xNCM-treated noNX-IVDs and two NCM+MSC-treated noNX-IVDs. As expected, the NX procedure induced all parameters, while $2 \times \mathrm{NCM}$ did not induce any of the parameters in NX-IVDs.

For histological analysis, all IVDs were scored (Boos grading validated for dogs [23]; score increases with degeneration (0-29)). At $\mathrm{T}=6$ months, only CLCs were present in all NPs (Figure 5A, 5B). Only in 2x
NCM-treated NPs, Picrosirius Red (collagen) staining was observed (Figure 5A, 5B). Furthermore, the median total Boos score significantly increased in control NXIVDs versus control noNX-IVDs ( $p<0.05$; Figure 5C) with six points (from 14 to 20 ), indicating that moderate IVD degeneration was induced. Only 2xNCM tended to improve the median Boos score compared with control NX-IVDs with three points ( $p=0.18$, medium ES). Boos score subcriteria indicated no differences between conditions for AF morphology, CLC morphology and proliferation in the NP, presence of NCs (none), matrix staining of the NP, and new bone formation (Figure 5A, $5 \mathrm{~B}, 5 \mathrm{D})$. The histologic score for chondrocyte metaplasia and tear and cleft formation in the AF (data not shown) and EP morphology (irregularity, thickness; Figure $5 \mathrm{E}$ ) of control NX-IVDs tended to be increased versus control noNX-IVDs ( $p=0.12-0.16$, medium-large ES). Additionally, the median subchondral bone sclerosis score was significantly increased in control NX-IVDs versus control noNX-IVDs $(p<0.05$; Figure 5F). In NX-IVDs, 2xNCM tended to improve the median EP morphology and subchondral bone sclerosis score versus controls ( $p=0.18$, medium ES). Taken together, EP irregularity and bone sclerosis was induced by NX, while 2xNCM inhibited these pathological processes.

At $\mathrm{T}=6$ months, the DNA content of the NP and AF tissue did not significantly differ, regardless the treatment and induction of degeneration (Figure 6A, 6B). SRY DNA was undetectable in the female IVDs in which male MSCs were injected, indicating that the male MSCs had not survived.

The NP and AF GAG content was not different between noNX-IVDs and NX-IVDs at $\mathrm{T}=6$ months (Figure 6C-6D), but was significantly lower in NPs from NX-IVDs versus NPs from noNX-IVDs $(p<0.05$, Supplementary File 2I, 2K) at $\mathrm{T}=0$ months (six weeks after NX). Thus, the decreased GAG content of NPs from IVDs in which moderate degeneration was induced (observed at $\mathrm{T}=0$ months) recovered to baseline levels at $\mathrm{T}=6$ months, suggesting an attempt at repair. This repair was further augmented by NCM: at $\mathrm{T}=6$ months, $1 \times N C M$ significantly increased the NP GAG content in noNX-IVDs versus control- and MSC-treated noNX-IVDs $(p<0.05)$. Also NCM+MSC treatment tended to increase the NP GAG content versus control noNX-IVDs ( $p=0.07$ with large ES). Moreover, in NX-IVDs, MSC and 2xNCM treatment significantly decreased the AF GAG content compared with noNX-control IVDs $(p<0.05)$, indicating less AF chondrification, a hallmark of the degenerative process.

The collagen content of control NX-IVDs was significantly higher versus control noNX-IVDs (NP: $p<0.05$, AF: $p<0.01$ ), indicating that collagen deposition increased with degeneration (Figure 6E$6 \mathrm{~F}$ ). In noNX-IVDs, 1xNCM significantly increased the NP collagen content versus control and $2 \times \mathrm{NCM}$ 
A
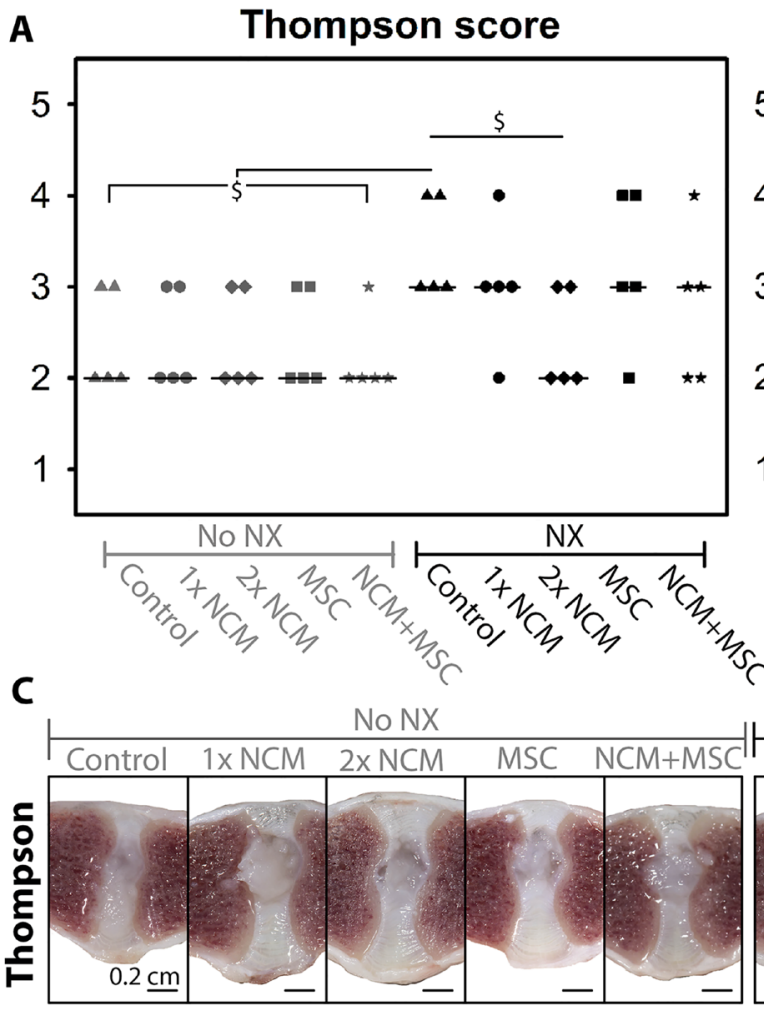

B Pfirrmann score
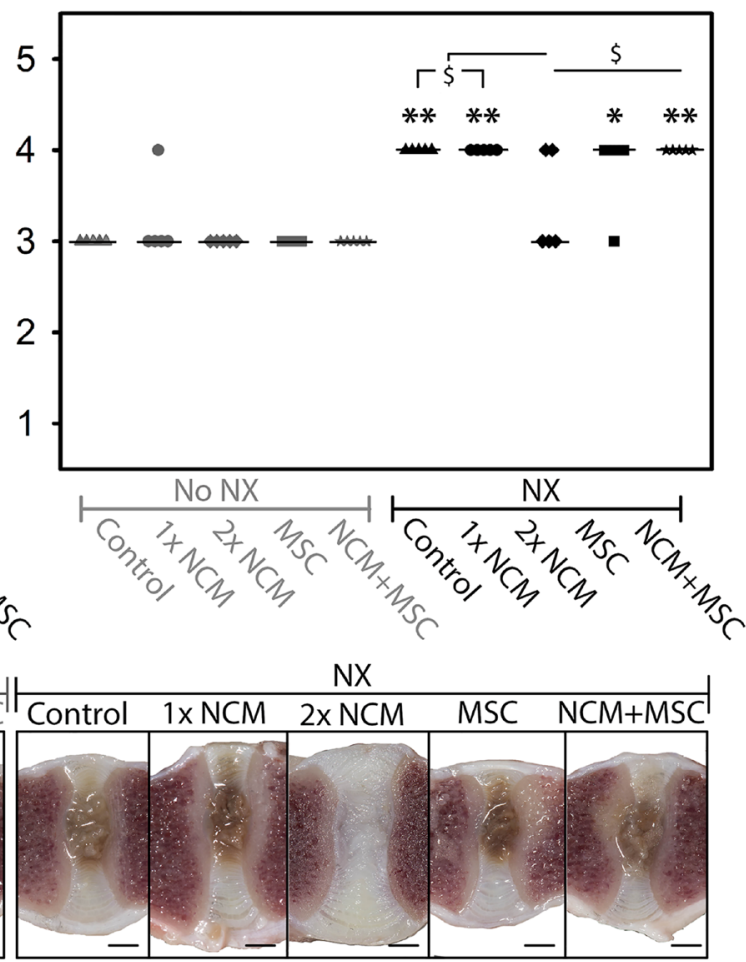

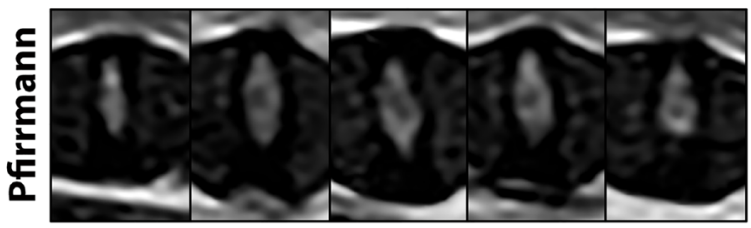

D
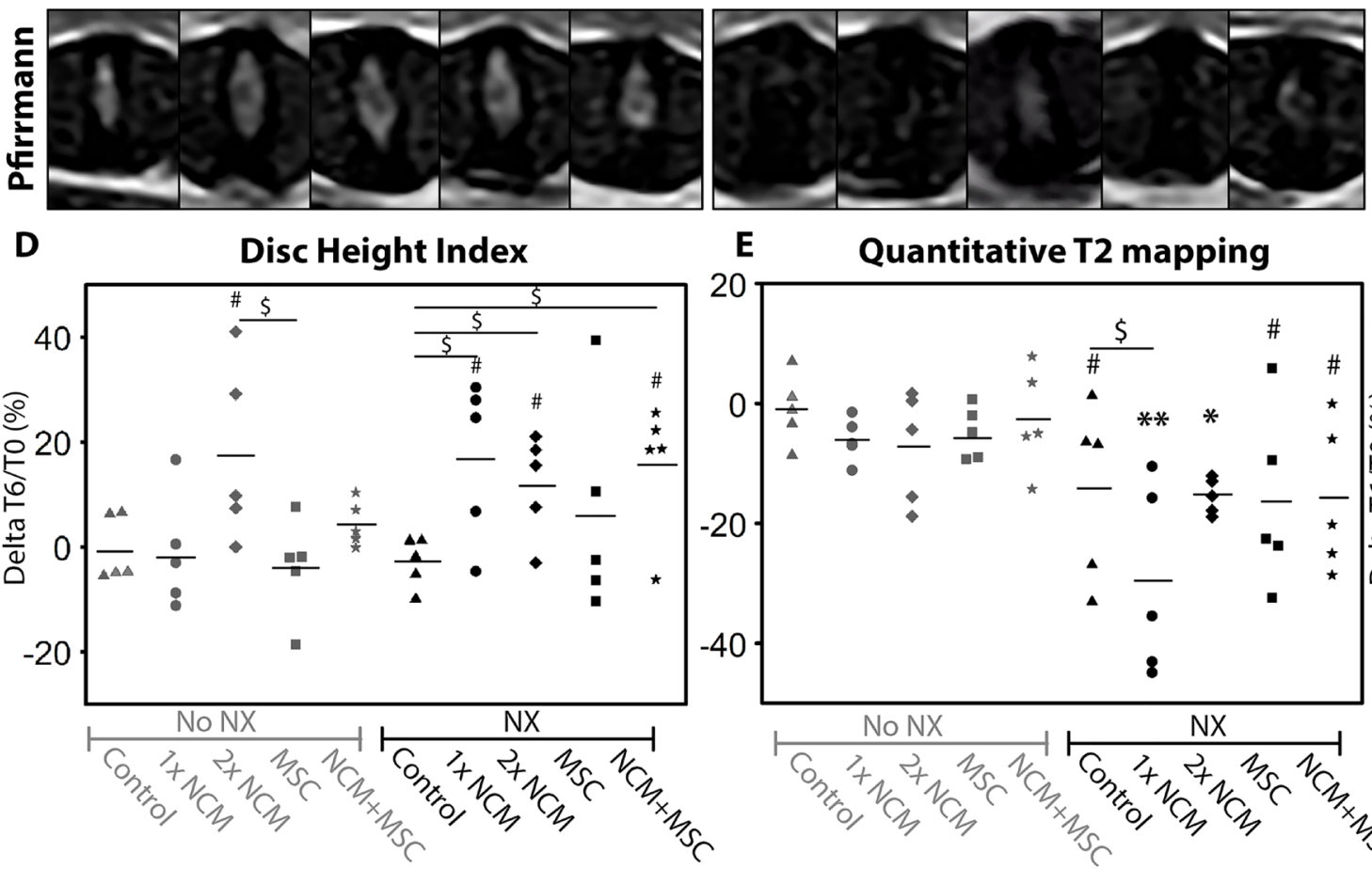

\section{E Quantitative T2 mapping}

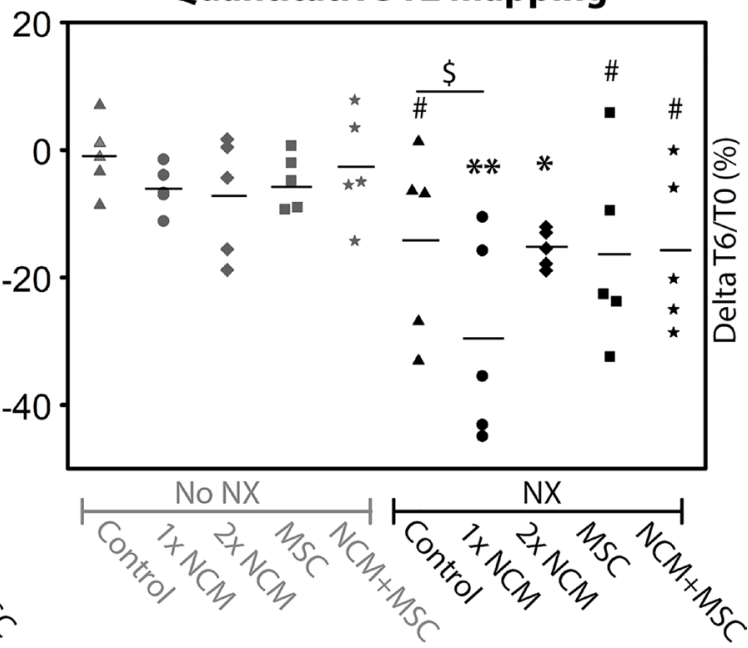

Figure 4: Notochordal cell-derived matrix (NCM) improves the macroscopic Thompson score and radiologic parameters of degenerated intervertebral discs (IVDs). Median (Thompson (A), Pfirrmann (B)) and mean (Disc Height Index; DHI (D), T2 values (E)) values are indicated. (C) Macroscopic and MRI pictures of the canine IVDs. Change in DHI and T2 mapping values were calculated at individual intervertebral disc (IVD) level. NX: partial nucleus pulposus (NP) removal to induce moderate IVD degeneration. ${ }^{* * * *} p<0.05, p<0.01$, respectively for the indicated condition versus control noNX-IVDs; ${ }^{*} p=0.05-0.15$, large effect size, for the indicated condition versus control noNX-IVDs; ${ }^{s} p=0.05-0.15$, large effect size, between indicated conditions; $n=5$. For Thompson and Pfirrmann data, a Mann-Whitney Wilcoxon test and for DHI and quantitative T2 mapping, a Cox proportional hazard model (donor as random effect) was performed with Benjamini \& Hochberg tests. For comparisons with $0.05 \geq p \leq 0.20$, effect sizes (Cliff's delta) were determined. 

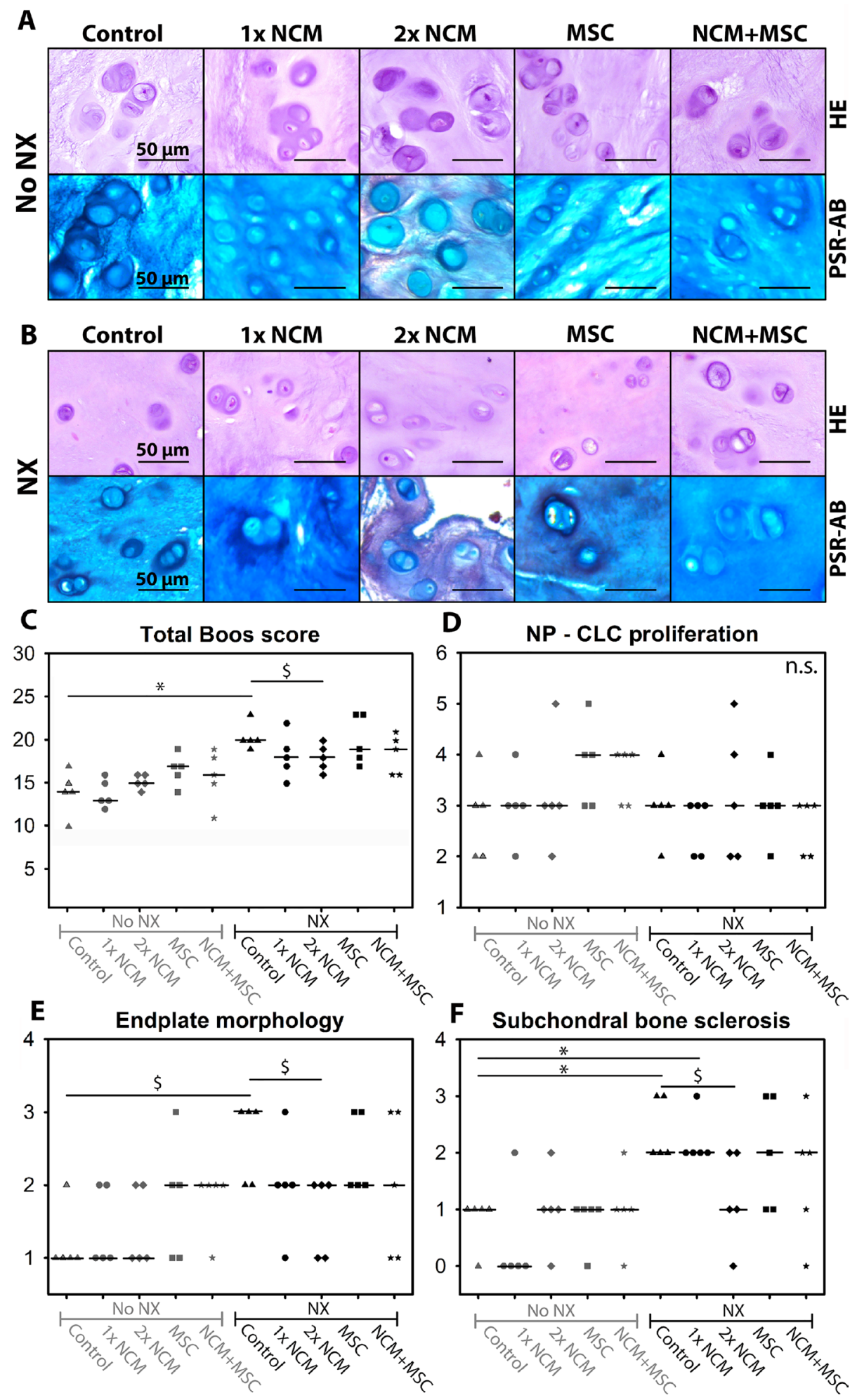

Figure 5: Notochordal cell-derived matrix (NCM) improves canine intervertebral disc (IVD) histology. H\&E and Picrosirius Red-Alcian Blue (blue: glycosaminoglycan, red: collagen) staining of canine nucleus pulposus tissue (A, B). Total histologic Boos score (C) and its subsets: chondrocyte-like (CLC) proliferation in the nucleus pulposus (NP; D), end plate morphology (E), and subchondral bone sclerosis (F). Median values are indicated. NX: partial NP removal to induce moderate IVD degeneration. n.s.: not significant; ${ }^{*} p<0.05$ between indicated conditions; ${ }^{\$} p=0.05-0.18$ with medium-large effect size between indicated conditions; $n=5$. Data were analyzed with Mann-Whitney Wilcoxon and Benjamini \& Hochberg tests. For comparisons with $0.05 \geq p \leq 0.20$, effect sizes (Cliff's delta) were determined. 
$(p<0.05)$. Additionally, 1xNCM, 2xNCM, and $\mathrm{NCM}+\mathrm{MSC}$ significantly increased the AF collagen content versus controls in noNX-IVDs. In NX-IVDs, $2 \mathrm{xNCM}$ significantly increased the NP collagen content versus control, MSC, and MSC+NCM $(p<0.05)$. Lastly, the AF collagen content was significantly reduced by all treatments versus controls in NX-IVDs $(p<0.05)$. To determine the types of collagen that were deposited, immunohistochemistry was performed. Collagen type I was present in the AF (not differentially expressed; data not shown), but not in the NP (Figure 7), suggesting the absence of NP fibrosis. Collagen type II was present in all

\section{A Nucleus pulposus}

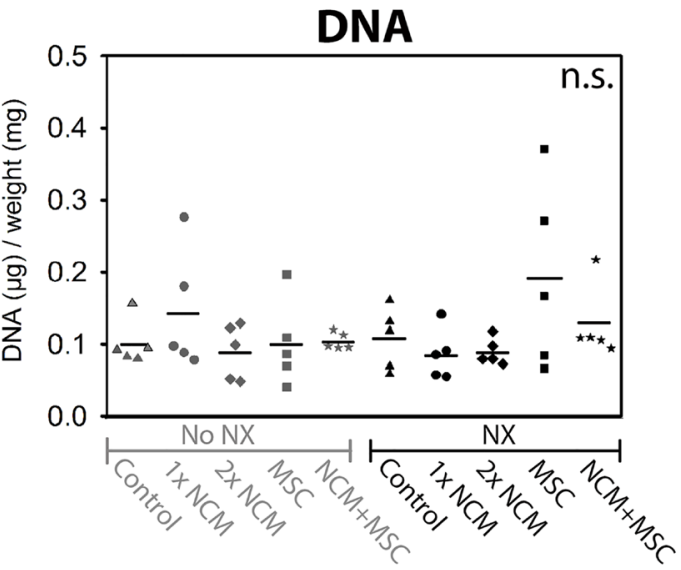

C
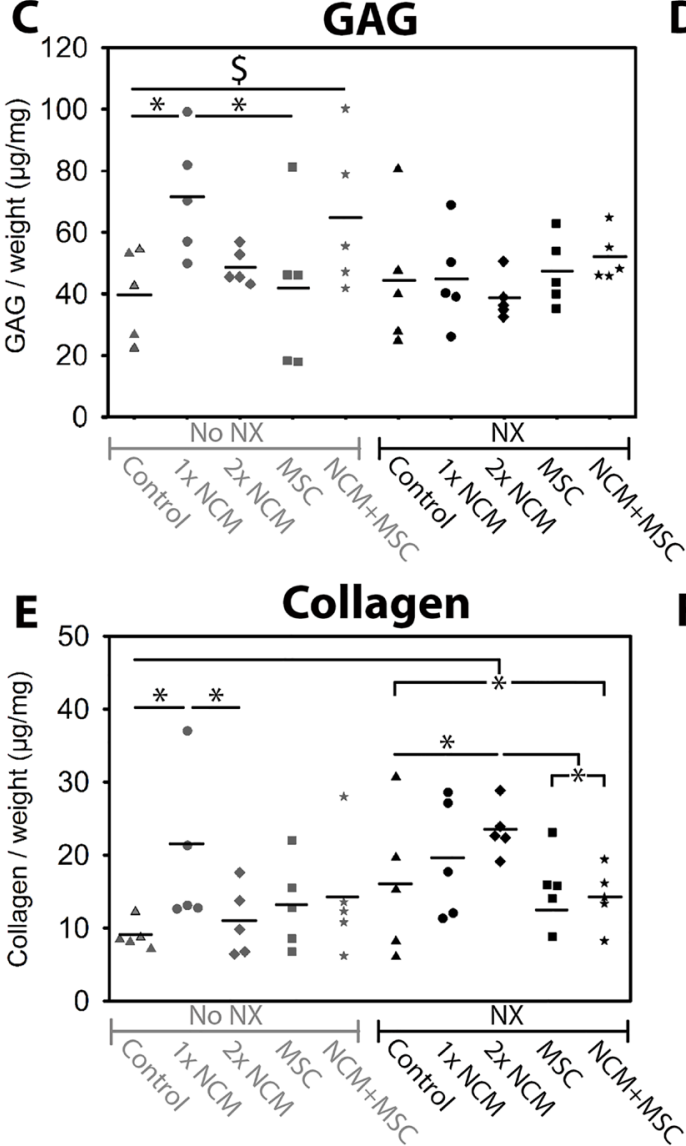

B Annulus fibrosus DNA

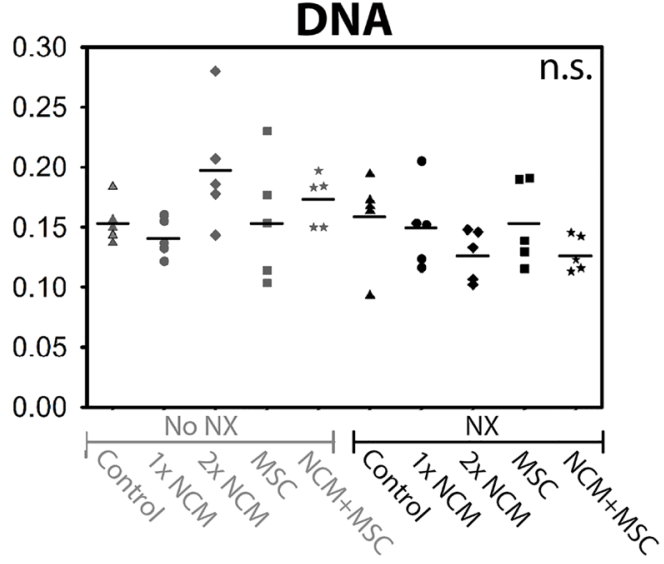

D

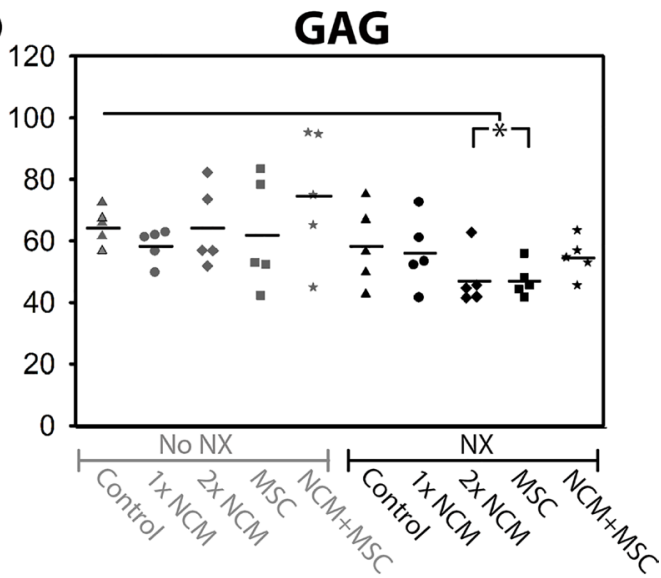

$\mathbf{F}$

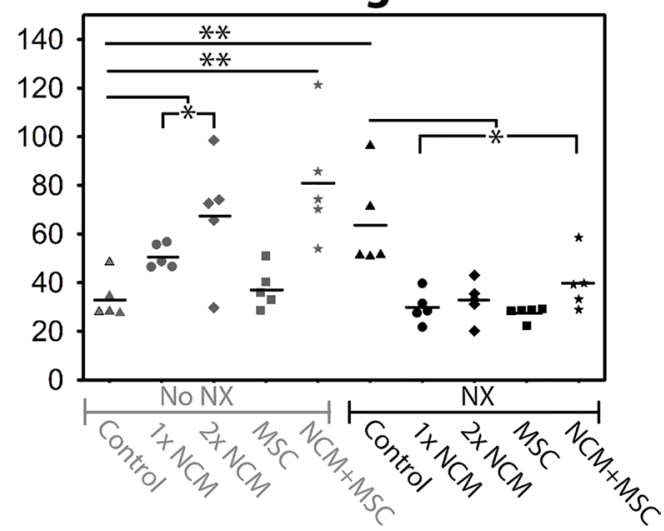

Figure 6: The effect of notochordal cell-derived matrix (NCM) on the DNA (A, B), glycosaminoglycan (GAG; C, D), and total collagen $(\mathbf{E}, \mathbf{F})$ content of the nucleus pulposus (NP) and annulus fibrosus (AF). Mean values are indicated. NX: partial NP removal to induce moderate IVD degeneration. n.s.: not significant; ${ }^{* * * *} p<0.05, p<0.01$, respectively, between indicated conditions; ${ }^{\$} p=0.07$, large effect size between indicated conditions; $n=5$. Data were analyzed with randomized block design ANOVAs and Benjamini \& Hochberg tests. For comparisons with $0.05 \geq p \leq 0.20$, effect sizes (Hedge's g) were determined. 
NPs (Figure 7). In noNX-IVD NPs, collagen type II was most abundantly present after 1xNCM treatment, while in NX-IVD NPs it was most abundantly deposited by $1 \mathrm{xNCM}$ and 2xNCM. Collagen type $\mathrm{X}$ was undetectable regardless the treatment (Figure 7), indicating absent hypertrophic differentiation.

Altogether, NCM induced collagen type II-rich matrix deposition in vivo. NCM is enriched in collagen and GAGs. Injection of $50 \mu \mathrm{L}$ of $10 \mathrm{mg} / \mathrm{mL} \mathrm{NCM}$ (containing both $5 \mathrm{mg} / \mathrm{mL}$ GAGs and collagen) would contribute to $0.25 \mathrm{mg}$ GAG and collagen per treated IVD. While 2xNCM increased the NP collagen content, it did not augment the NP GAG content of NX-IVDs. Since GAGs attract water and the biochemical data were corrected for wet weight, we possibly missed the presence of an increased GAG content (per mg dry weight).
At $\mathrm{T}=6$ months, no differences in NP mRNA expression were established between conditions for ECMrelated genes $S O X 9$, ACAN, COL1A1, COLX, ADAMTS5 and $M M P 13$ (data not shown). This indicates the limited translatability of gene expression data in view of the longterm follow-up period of six months. COL2A1 mRNA expression was, however, increased in all NX-IVDs versus control noNX-IVDs $(p<0.05$ or $p=0.07$ with large ES; Supplementary File 4A). In NX-IVDs, 2xNCM tended to increase $C O L 2 A 1$ expression versus all other treatments $(0.05 \geq p \leq 0.17$, medium ES). TIMP expression tended to be increased in NX-IVDs treated with 1xNCM, 2xNCM, MSCs and NCM+MSCs versus control noNX-IVDs $(p<0.05$, or $p=0.14$ with medium ES; Supplementary File 4B). Altogether, NCM induced an anabolic effect by increasing the expression of the anti-catabolic TIMP

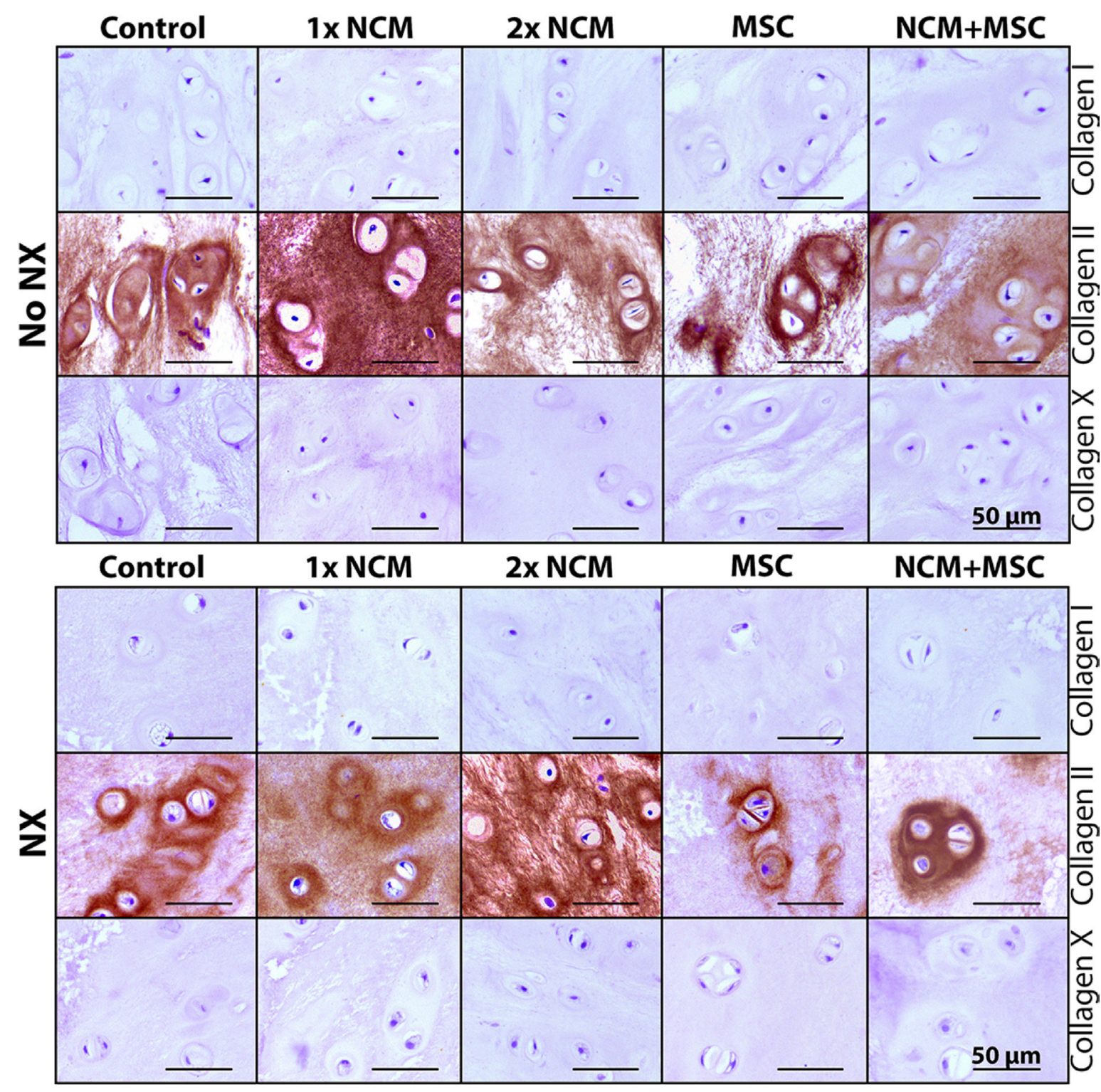

Figure 7: Notochordal cell-derived matrix (NCM) stimulates collagen type II, but no collagen type I or X deposition in the canine nucleus pulposus (NP) in vivo. NX: partial NP removal to induce moderate IVD degeneration. $n=5$. 
gene and by inducing $C O L 2 A 1$ expression. The latter is in line with the augmented collagen type II deposition (IHC). Expression of the cell proliferation- and apoptosisrelated genes $C C N D 1, C A S P 3, B C L 2$, and $B A X$ was not different between conditions (data not shown). Regarding NP specific markers, 2xNCM induced KRT18 and KRT19 expression in mildly degenerated IVDs, and reduced their expression in moderately degenerated IVDs $(p=0.01-$ 0.10, medium-large ES; Supplementary File 4C-4D). $P A I 1$ expression was significantly induced by $2 \mathrm{xNCM}$ in NX-IVDs $(p<0.05$; S4E), suggesting increased TGF- $\beta$ signaling at mRNA level.

To determine the treatment effect on inflammation, cycloxygenase-2 (COX-2) IHC and RT-qPCR were performed, and the prostaglandin E2 (PGE2) content of the IVD tissues was determined. COX-2 immunopositivity was present in every NP (Figure 8A) and AF. On average, $7-20 \%$ of canine CLCs in the NP expressed cytoplasmic COX-2, with no differences between conditions (data not shown). ILI $\beta$ and TNF $\alpha$ (pro-inflammatory cytokines) expression was not different between control noNX- and NX-IVD NPs (Figure 8B-8C). In NX-IVDs, however, $2 \mathrm{xNCM}$ tended to reduce $I L 1 \beta$ and $T N F \alpha$ expression ( $p$ $=0.09$ and 0.11 , medium ES). Control NX-IVDs showed a higher PGE2 content than control noNX-IVDs (NP: $p<0.05$, AF: $p=0.06$, very large ES; Figure 8D-8E), indicating that PGE2 levels (indicative of increased COX2 activity) increased with degeneration. In line with RTqPCR results, $2 x N C M$ significantly decreased the NP and AF PGE2 content in NX-IVDs ( $p<0.05$, large effect size). Altogether, NCM ameliorated inflammation in moderately degenerated IVDs.

\section{DISCUSSION}

The spine field has already demonstrated the regenerative potential of NCs [5-12]. The present innovative study demonstrates that by employing healthy NC-derived NP tissue matrix, we can harness the NC regenerative potential and exploit it for biological IVD repair. As a first step towards bench-to-bedside translation, we demonstrate that NCM exerted regenerative effects on canine and human CLCs from degenerated IVDs in vitro and on canine IVDs in vivo by inducing anabolic effects and ameliorating inflammation. The question arises how NCM exerts its anabolic effects. It may serve as 'instructive matrix', locally increasing growth factor concentrations and promoting their biological activity [24]. In this respect, NCM may be comparable to DMB, which is successfully employed in clinical practice. DBM induces bone regeneration by providing a degradable matrix that facilitates the release and modulates the accessibility of growth factors normally present in bone [15]. Increased PAII (TGF- $\beta$ pathway target gene) expression in 2xNCM-treated IVDs indeed indicates augmented Smad signalling. The exact mechanism of action of NCM remains to be determined and is most probably a combination of bioactive factors retained within NCM and ECM molecules modulating their activity [25].

\section{MSCs do not exert distinct effects in the degenerated canine IVD in vivo}

Intradiscal allogeneic MSC delivery is considered a promising IVD regeneration strategy. MSC transplantation was not accompanied by osteophyte formation (a possible complication [26]), most probably because a polymerized hydrogel, which prevents leakage, was used as carrier or because the MSCs did not thrive in vivo. Although we detected male DNA (MSCs) in the female IVDs immediately after intradiscal injection, male DNA was undetectable after six months. This result contrasts with previous Beagle studies, in which autologous transplanted MSCs could be traced back up to twelve months and exerted beneficial effects [27-29]. This contradiction, however, needs to be cautiously interpreted, since only one quart of IVD tissue was available for SRY analysis, so low numbers of surviving MSCs were possibly missed. Nevertheless, transplanted MSCs, capable of multilineage differentiation in vitro, did not exert beneficial effects in vivo, alone or combined with NCM. MSC populations are known to exhibit considerable donor-to-donor and intra-population heterogeneity [30], and in the harsh environment of the degenerated IVD, this could have contributed at best to a transient trophic effect which was not biologically relevant at longterm follow-up.

\section{Intradiscally applied NCM has a regenerative effect on degenerated canine IVDs}

The present study demonstrates that NCM exerted regenerative effects on MSCs and CLCs derived from degenerated IVDs in vitro. Although canine CLCs seemed to be more responsive to NCM than human CLCs, NCM exerted an anabolic effect and increased the DNA content (number of cells/micro-aggregate) in both species, in line with previous work on decellularized bovine NP ECM [31].

Based on these promising results, an in vivo study was performed. In mildly degenerated IVDs, NCM upregulated mRNA expression of NP-specific markers, augmented the NP GAG and collagen content, and hence seemed to favor IVD health. Notably, in moderately degenerated NX-IVDs, NCM-mediated effects were more pronounced. Mainly 2xNCM exerted beneficial effects on the NPs from NX-IVDs: the macroscopic Thompson, histologic Boos (total, end plate morphology, and subchondral bone sclerosis score) and MRI-based Pfirrmann score were improved. Additionally, the DHI of 1xNCM-, 2xNCM- and NCM+MSC-treated NX-IVDs increased during the study. Given that MSC injection alone was not able to increase the DHI, this beneficial 
effect is presumably NCM-specific. Since 2xNCM induced collagen type II, but no collagen type I and X expression, NP-like ECM, but no fibrotic or hypertrophic ECM $[32,33]$ was deposited. Lastly, 2xNCM was able to exert protective effects on the L7-S1 IVD, a junction that permits the highest range of motion [34] and predisposes this IVD to a high degree of wear and tear. Altogether, these findings imply an NCM-dependent regenerative response, resulting in beneficial quantitative and qualitative ECM changes.
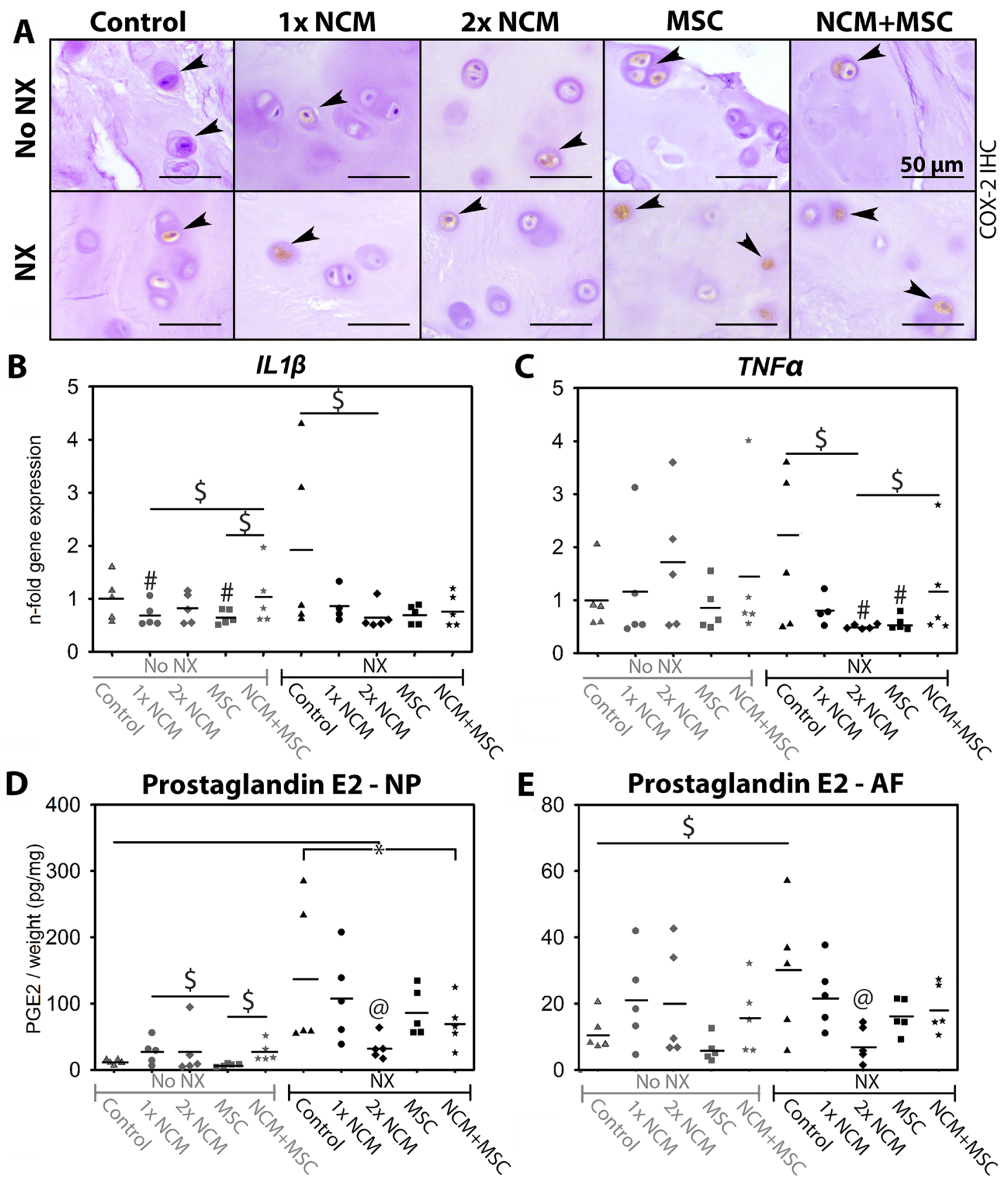

Figure 8: Notochordal cell-derived matrix (NCM) ameliorates inflammation in canine intervertebral discs (IVDs) in vivo. Cyclo-oxygenase-2 (COX-2) positive chondrocyte-like cells (CLCs) in the canine nucleus pulposus (NP) are indicated with arrowheads (A). Relative $I L 1 \beta$ (B) and $T N F \alpha(\mathbf{C})$ expression (control noNX-IVDs were set at 1) of canine NPs, and prostaglandin E2 (PGE2) content $(\mathbf{D}, \mathbf{E})$ of canine IVDs at $\mathrm{T}=6$ months are given with indicated mean values. AF: Annulus fibrosus. NX: partial NP removal to induce moderate IVD degeneration. ${ }^{*} p<0.05$ between indicated conditions; "different from control noNX-IVDs $(0.05 \geq$ $p \leq 0.20$, medium/large ES); $\$$ : difference between indicated conditions with medium/large effect size $(0.05 \geq p \leq 0.20)$; @: different from all other conditions in which NX was performed ( $p<0.05$ or $p<0.1$ with large effect size), $n=5$. PGE2 data were analyzed with a randomized block design ANOVA. For RT-qPCR data, a Cox proportional hazard test was performed (donor random effect). For comparisons with $0.05 \geq p \leq 0.20$, effect sizes (Hedge's g and Cliff's delta) were determined. Benjamini \& Hochberg tests were performed. 


\section{Quantitative T1 $\rho$ and T2 mapping did not detect NCM-mediated effects}

In contrast with other readout parameters, $\mathrm{T} 1 \rho$ and T2 mapping did not detect NCM-mediated regenerative effects. T1 $\rho$ is sensitive for interactions between macromolecules (e.g. GAGs) and water [35], while T2 mapping provides information regarding collagen, water and GAG content, ECM structure and orientation [36]. With the induction of degeneration, advanced glycation end products (AGEs) presumably accumulated [37, 38] and the NP collagen content increased, whereas T2 values decreased. These results are in agreement with previous studies demonstrating a negative correlation between $\mathrm{T} 2$ values and AGE accumulation [39]/collagen content $[40,41]$. Thus, IVD degeneration was detected by quantitative T2 mapping. In contrast, NCM-mediated regeneration (observed macroscopically, histologically, biochemically and according to MRI-based Pfirrmann grading) was not detected with T1 $\rho$ or T2 mapping. Noteworthy, T1 $\rho$ and T2 mapping have been specifically validated for IVD degeneration, but not for regeneration, which does not necessarily follow an identical reverse process. Lastly, T1 $\rho$ and $\mathrm{T} 2$ mapping are influenced by ECM structure/orientation and the water, GAG (both positively correlated with T2 vaules), and collagen (negatively correlated with $\mathrm{T} 2$ values) content of the NP [35, 36], making it difficult to detect regenerative changes when more than one of these parameters is affected by the treatment.

\section{NCM exerts anti-inflammatory effects in degenerated canine IVDs in vivo}

Besides beneficial effects on macroscopic, radiologic, biochemical, and histological level, NCM also exerted anti-inflammatory effects on degenerated IVDs in vivo. The PGE2-producing enzyme COX-2 was uniformly present in NPs, implying local PGE2 synthesis. PGE2 levels were, however, decreased by $2 x N C M$ in NX-IVD NPs, indicating that $2 \mathrm{xNCM}$ decreased COX-2 activity and inhibited inflammation. In line with this, all NX-IVD NPs, except 2xNCM-treated NPs, showed a brown discoloration. This brown color was presumably caused by accumulation of AGEs. AGEs are formed through non-enzymatic glycation of amino residues and oxidation of fatty acids during IVD degeneration [37, 38] and can act as pro-inflammatory mediator [42]. Altogether, 2xNCM may prevent AGE accumulation in degenerated IVDs, thereby exerting an anti-inflammatory effect. This hypothesis is confirmed by the decreased PGE2 content and downregulated IL1 $\beta$ and TNF $\alpha$ expression in $2 \times N C M-$ treated NX-IVDs. These anti-inflammatory NC properties have already been demonstrated previously [43].

\section{Limitations and future directions}

The present study demonstrates that $10 \mathrm{mg} / \mathrm{mL}$ NCM exerted beneficial effects on canine and human
CLCs from degenerated IVDs in vitro and degenerated Beagle IVDs in vivo. Given that $0.5 \mathrm{mg} \mathrm{NCM} / \mathrm{IVD}$ exerted beneficial effects, it is tempting to hypothesize that higher $\mathrm{NCM}$ dosages may further improve the regenerative and anti-inflammatory effects. After fine-tuning the dosedependent efficacy of NCM, follow-up studies should look into the application of NCM in hydrogel form, which reduces the risk of leakage after intradiscal injection. Furthermore, for safe (veterinary and human) clinical application, removal of nucleic acid from NCM should be achieved with preservation of bioactivity [31].

\section{MATERIALS AND METHODS}

\section{Overall study design}

The first objective of this study was to determine the effect of NCM (produced from porcine NC-rich tissue by lyophilization, pulverization, and resuspension at $10 \mathrm{mg} / \mathrm{mL}$ ) on human and canine CLCs in vitro. Porcine NCM was pooled $(n=6)$ to assess the its effect on a representative population of donor-specific (CLCs from) degenerated IVDs ( $n=6$ canine and $n=6$ human CLC donors). The second aim was to assess the effect of NCM in vivo on degenerated canine IVDs $(n=6$ Beagles, based on power analysis with power: $85 \%$, alpha: $0.8 \%$ and standard deviation $15-30 \%$, with disc height index as the primary read out parameter $[29,44])$. Also, the (additive) effect of MSCs was determined. One dog died during the intradiscal injections at $\mathrm{T}=0$ months (cause of death unrelated to treatment) and therefore, at $\mathrm{T}=6$ months, the IVDs of the five remaining Beagles were analyzed. We hypothesized that NCM would exert regenerative effects on canine and human CLCs in vitro and degenerated canine IVDs in vivo and that MSCs would have an additive effect. For the in vivo experiment, NCM, MSCs and $\mathrm{NCM}+\mathrm{MSCs}$ were intradiscally injected in mildly (spontaneously) and moderately (induced by partial NP removal) degenerated canine IVDs (Figure 9). Treatments were not randomized within each dog to prevent interference of random effects from the spinal segment. After three months, NCM was reinjected in two degenerated IVDs per dog (2x NCM) to determine whether multiple injections would exert a more beneficial effect. Longitudinal quantitative MRI was performed and IVDs were macroscopically, histologically, and biochemically analyzed after six months. Outliers were not excluded. The investigators who assessed, measured, or quantified the results were blinded to the intervention.

\section{Generation of NCM}

Thompson score I, healthy IVD tissue was collected from complete spines of six 3-month-old porcine donors from the slaughterhouse in accordance with local regulations (permit 457642.09). To produce NCM, NP tissue was lyophilized overnight, pulverized to 
fine powder using a microdismembrator (Sartorius) and resuspended at $10 \mathrm{mg} / \mathrm{mL}$ in hgDMEM+Glutamax (31966, Invitrogen). For in vitro studies, NCM was supplemented with 1\% P/S (P11-010, GE Healthcare Life Sciences), $1 \%$ ITS+ premix (354352, Corning Life Sciences), 0.04 $\mathrm{mg} / \mathrm{mL}$ L-proline (P5607, Sigma-Aldrich), $0.1 \mathrm{mM}$ Ascorbic acid 2-phosphate (Asap; A8960, Sigma-Aldrich), and $1.25 \mathrm{mg} / \mathrm{mL}$ Bovine Serum Albumin (BSA; A9418, Sigma-Aldrich).

\section{The effect of NCM on canine and human CLCs and MSCs in vitro}

IVDs from complete spines were collected from six Beagles (2-7 years of age, three male/three female, Thompson score III) euthanized in unrelated research studies (approved by the Utrecht University Animal Ethics Committee, experimental numbers: 2012.III.07.065, 2013. III.02.017, and 2013.II.12.126). Additionally, IVDs from six human donors (47-72 years of age, three male/three female, Thompson score III) were obtained during a standard post-mortem diagnostics ( $<48$ hours after death). The L2-L5 part of the spine was collected, approved by the scientific committee of the Pathology department of the University Medical Centre Utrecht (UMCU). Anonymous use of redundant tissue for research purposes is a standard agreement with UMCU patients (Local Medical Ethical Committee number 12-364). The IVDs were used according to the code 'Proper Secondary Use of Human Tissue', installed by the Federation of Biomedical
Scientific Societies. The NP was collected by precise separation from AF and EPs and digested by $0.15 \%$ pronase (45 $\mathrm{min}$ ) and $0.15 \%$ collagenase (overnight) treatment. The CLCs were stored in hgDMEM+Glutamax with $10 \%$ fetal bovine serum and $10 \% \operatorname{DMSO}\left(-196^{\circ} \mathrm{C}\right)$ until use.

Canine and human CLCs were expanded at 5\% $\mathrm{O}_{2}$, $5 \% \mathrm{CO}_{2}, 37^{\circ} \mathrm{C}$ until passage 2 as described previously [5]. Additionally, bone marrow-derived MSCs from three canine donors (two 4-month old Labrador Retrievers, one 3-year old Beagle, male) were isolated, expanded, and characterized as described previously [45]. Microaggregates of 35,000 CLCs or MSCs were formed as described previously [5]. Briefly, CLCs/MSCs were plated in low-adherence cell-repellent surface 96-well plates (650970, CELLSTAR ${ }^{\circledR}$ Greiner Bio-one) in $50 \mu \mathrm{L}$ basal culture medium (hgDMEM+Glutamax with $1 \% \mathrm{P} / \mathrm{S}, 1 \%$ ITS+ premix, $0.04 \mathrm{mg} / \mathrm{mL}$ L-proline, $0.1 \mathrm{mM}$ Asap, 1.25 $\mathrm{mg} / \mathrm{mL}$ BSA). CLC micro-aggregates ( $n=6$, in duplicates) were cultured in basal culture medium for (negative) control micro-aggregates, supplemented with $10 \mathrm{ng} / \mathrm{mL}$ human recombinant TGF- $\beta_{1}(240-\mathrm{B}, \mathrm{R} \& \mathrm{D}$ Systems) as positive control (to show that the canine and human CLC donors were able to produce GAGs if a proper stimulus was provided, e.g. in case these donors would not respond to $\mathrm{NCM})$, or $10 \mathrm{mg} / \mathrm{mL} \mathrm{NCM}$. MSC micro-aggregates $(n=3$, in duplicates) were cultured in (a) basal culture medium supplemented with $0.1 \mu \mathrm{M}$ dexamethasone (D8893, Sigma Aldrich) (control), (b) supplemented with $10 \mathrm{ng} / \mathrm{mL}$ TGF- $\beta_{1}$ (positive control), or (c) $10 \mathrm{mg} / \mathrm{mL}$ NCM. Micro-

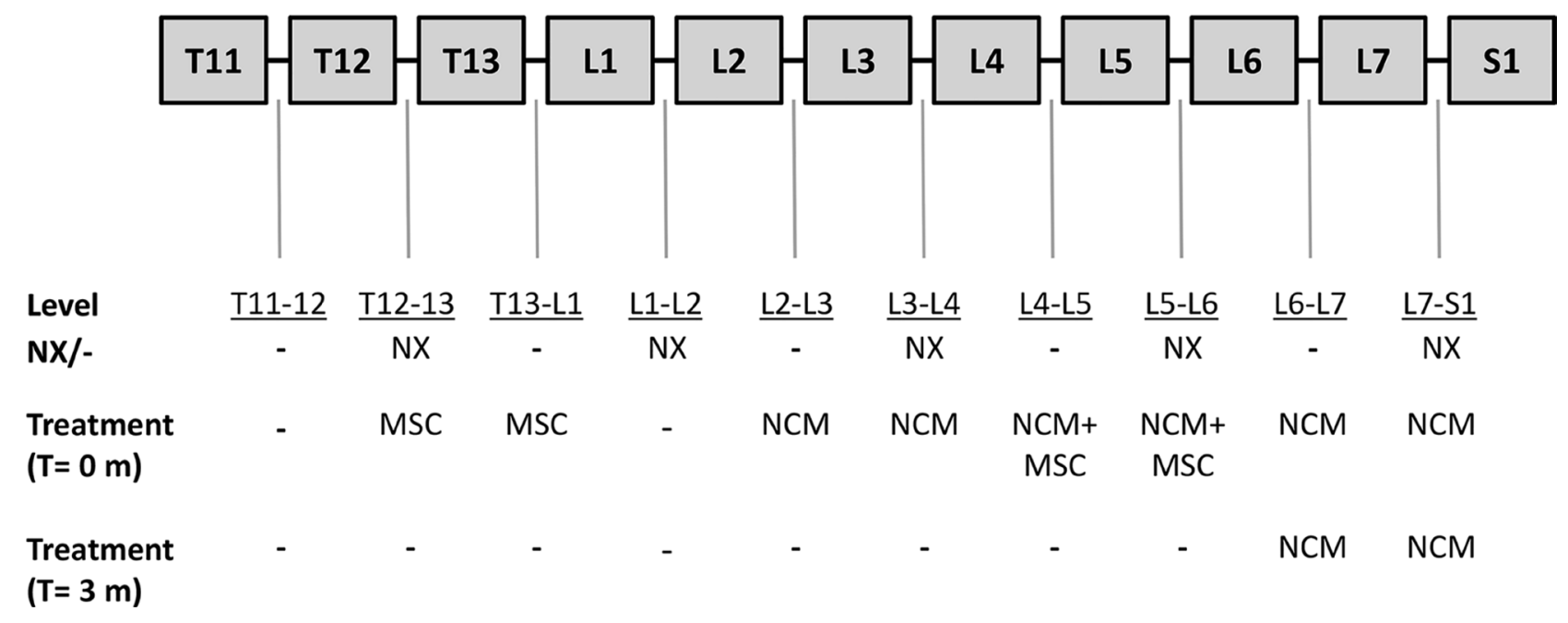

Figure 9: Overview of the intradiscal treatment per canine intervertebal disc (IVD). Six weeks before the start of the experiment ( $\mathrm{T}=-1.5$ months), more severe (moderate) IVD degeneration was induced in five IVDs per dog by partial nucleus pulposus (NP) removal (NX; T12-T13, L1-L2, L3-L4, L5-L6, and L7-S1) on the left side of the spine. At the start of the experiment (T = 0 months), the mildly and moderately degenerated canine IVDs were injected on the right side of the spine with $50 \mu \mathrm{L}$ of (a) $1^{*} 10^{6}$ canine mesenchymal stromal cells (MSCs) incorporated in an albumin-based hydrogel, (b) $10 \mathrm{mg} / \mathrm{mL}$ notochordal cell-derived matrix (NCM), or (c) $1^{*} 10^{6}$ canine MSCs suspended in $10 \mathrm{mg} / \mathrm{mL}$ NCM. Three months after the first injections ( $\mathrm{T}=3$ months), two IVDs per dog (L6-L7 and L7-S1) were again injected with $50 \mu \mathrm{L}$ of $10 \mathrm{mg} / \mathrm{mL}$ NCM. Every dog received a similar treatment per spinal location. -: no NX/no treatment. $n=6$ dogs. One dog died unexpectedly at $\mathrm{T}=0$ (cause of death unrelated to treatment) and the IVDs of this dog were used as baseline values. At $\mathrm{T}=6$ months, the other five dogs were euthanized and their IVDs were analyzed. 
aggregates were cultured for 28 days at $5 \% \mathrm{O}_{2}, 5 \% \mathrm{CO}_{2}$, $37^{\circ} \mathrm{C}$. Culture medium was changed twice weekly.

The DNA (dsDNA High Sensitivity Assay Kit, Invitrogen) and GAG content (DMMB assay [46]) were determined at day 28, and Safranin $\mathrm{O} /$ Fast Green staining and immunohistochemistry for collagen type I, II, and X were performed at day 28 ( $n$ $=6$, in duplicates) as described previously [5]. Sulphate incorporation (measure for proteoglycan synthesis rate) was determined during the last 4 hours of a 7-day culture period as described previously [47] (details in Supplementary File 5A).

\section{Experimental setup of the in vivo study}

Procedures were approved and conducted in accordance with Animal Experiments Committee guidelines (project number: AVD108002015285), required by Dutch regulation. Six intact female Beagles (14 months of age, weight $10-11 \mathrm{~kg}$ ) were purchased from Marshall BioResources. Bone marrow-derived MSCs were obtained from one 3-year old male canine donor (Beagle, similar donor as used in in vitro experiment, euthanatized for unrelated experiments (2012.III.07.065) to enable tracking of male DNA (MSCs) in female IVDs.

The effect of NCM, MSCs and a combined treatment of $\mathrm{NCM}+\mathrm{MSCs}$ was tested on mildly and moderately degenerated canine IVDs (Figure 9). Six weeks before the intradiscal injections ( $\mathrm{T}=-1.5$ months), dogs underwent a general, orthopedic and neurologic clinical examination by veterinarians (FB, AT). Additionally, more severe (moderate) IVD degeneration was induced in five IVDs per dog by a board-certified veterinary surgeon $(\mathrm{BM})$ via partial NP removal $(\mathrm{NX})$ on the left side of the spine. At $\mathrm{T}=0$ months, MRI analysis was performed to determine the degree of IVD degeneration. Thereafter, the IVDs in which no NX was performed (noNX-IVDs; five per dog) and the IVDs in which NX was performed (NX-IVDs; five per dog) were either not injected (control) or injected on the right side of the spine with $50 \mu \mathrm{L}$ of (a) $1 \times 10^{6} \mathrm{MSCs}$ in a canine albumin-hyaluronan hydrogel [48] (b) $10 \mathrm{mg} / \mathrm{mL} \mathrm{NCM}$, or (c) $1 \times 10^{6} \mathrm{MSCs}$ suspended in $10 \mathrm{mg} / \mathrm{mL} \mathrm{NCM}$. At T $=3$ months, MRI analysis was performed and two IVDs per dog (L6-L7 (noNX-IVD) and L7-S1 (NX-IVD), which previously received $50 \mu \mathrm{L} \mathrm{NCM}$ ) were reinjected with $50 \mu \mathrm{L}$ of $10 \mathrm{mg} / \mathrm{mL} \mathrm{NCM}(2 \mathrm{x} \mathrm{NCM})$, to test whether a better effect could be achieved with multiple injections. At $\mathrm{T}=6$ months, MRI and CT analysis were performed, the dogs were euthanized, and the IVDs were collected. One dog died at $\mathrm{T}=0$ months during the first injection (cause of death unrelated with treatment). This dog was used to determine baseline degree of induced IVD degeneration and confirm the presence of transplanted MSCs.

\section{Induction of IVD degeneration}

Anesthesia and analgesia protocols are described in Supplementary File 5B. IVD degeneration was induced either by a left lateral (T11-T12 until L5-L6) or a dorsal (L6-L7 and L7-S1, assisted by mini-laminectomy) nuclectomy under fluoroscopic guidance by a boardcertified veterinary surgeon (BM). A $2 \mathrm{~mm}$ slit was made in the AF with a Beaver knife 65 and NP tissue (20-40 mg, dependent on IVD size) was collected using a $1 \mathrm{~mm}$ ball-tipped probe, and fixed in $4 \%$ neutral buffered formaldehyde. Five $\mu \mathrm{m}$ paraffin sections were stained with Hematoxylin (109249, Merck)/Eosin (115935, Merck) and Picrosirius Red (saturated aqueous picric acid: P6744, Sigma-Aldrich; sirius red: 365548, Sigma-Aldrich)/Alcian Blue (A5268, Sigma-Aldrich) [49]. All dogs uneventfully recovered from the induction surgery and were ambulant the next day.

\section{Preparation of MSCs for in vivo application}

Chondrogenic (Safranin O/Fast Green), adipogenic (Oil-Red-O), osteogenic (Alizarin Red S staining) differentiation and FACS analysis for positive (CD29 (303004, Biolegend), CD90 (12590042, Thermofisher scientific), CD105 (bs-4609R, Bioss antibodies)) and negative (CD34 (559369, BD Pharmingen), CD45 (LSC127720-100, LifeSpan BioSciences)) MSC markers $[50,51]$ was performed as described previously [45]. MSCs from the Beagle donor were expanded until passage 1 and incorporated in (a) albumin-hyaluronan hydrogels $\left(20 \times 10^{6} \mathrm{MSCs} / \mathrm{mL}\right.$ hydrogel $)$ or (b) $10 \mathrm{mg} / \mathrm{mL} \mathrm{NCM}\left(20 \times 10^{6} \mathrm{MSCs} / \mathrm{mL} \mathrm{NCM}\right)$ directly prior to injection. The hydrogels were composed of chemically activated canine albumin (Animal Blood Resources International), bisthio-polyethylene glycol, and hyaluronic acid.

\section{Intradiscal injections}

Intradiscal injections of T12-13 until L5-L6 were performed from the right side with $25 \mathrm{G}$ needles (Epican, 4502400, B.Braun). The L6-L7 and L7-S1 IVDs were percutaneously approached dorsally with $19 \mathrm{G}$ needles (301750, BD Microlance) that guided the 25G needles into the NP under fluoroscopic guidance (Supplementary File $2 \mathrm{G}-2 \mathrm{H})$. Once the needle was correctly placed according to fluoroscopic imaging, $50 \mu \mathrm{L}$ of the treatment volume was intradiscally administered by a boardcertified veterinary surgeon (BM) under visual control of the injection port. Leakage through the injection port was not observed. One dog died unexpectedly at $\mathrm{T}=0$ (cause of death unrelated to treatment) and the IVDs of this dog were used as baseline. The five other dogs uneventfully recovered from the injections and were ambulant the next day. One dog showed minor paresis and a reduction in 
spinal reflexes of the right hind limb related to the surgical approach, but recovered within seven days.

\section{MRI and CT}

Details for the magnetic resonance images (MRI) and computed tomography (CT) analysis are given in Supplementary File 5C. MRI T2 mapping and T1 $\rho$ values were computed by voxelwise fitting. The mean signal intensity in each region of interest was calculated using the Levenberg-Marquardt nonlinear least-squares method as described previously [52]. MRI images were blindly evaluated by two independent investigators (FB, MB; Pfirrmann score) [22]. The Pfirrmann score (grade $1-5$; grade 1 represents a healthy and grade 5 a severely degenerated IVD) is used to determine the degree of IVD degeneration, taking into account the structure and signal intensity of the NP, the distinction between NP and AF border, and the height of the IVD [22]. The Pfirrmann, and $\mathrm{T} 1 \rho$ and $\mathrm{T} 2$ mapping inter- and intraobserver reliability was excellent (intra-class correlation $>0.95$ ) [53]. Disc height index was calculated on T2W images according to the method described by Masuda et al. [54]. In short, the DHI was calculated by averaging the widths of the dorsal, middle, and ventral parts of the vertebral disc divided by the average of dorsal, middle, and ventral body heights of the adjacent cranial and caudal vertebrae.

\section{Sample collection, macroscopic and histopathological grading}

Details for samples collection are provided in Supplementary File 5D. IVD images were blindly evaluated by two independent investigators (FB, AT; Thompson score) [21]. The Thomson score (grade 1-5; grade 1 represents a healthy and grade 5 a severely degenerated IVD) is used to macroscopically determine the degree of IVD degeneration and includes all IVD units (AF, NP, EP and vertebrae) [21]. Inter-observer reliability was excellent (intra-class correlation: 0.85) [53]. Five $\mu \mathrm{m}$ sections were stained with $\mathrm{H} / \mathrm{E}$ and Picrosirius Red/ Alcian Blue (PSR/AB) and blindly evaluated (modified Boos score) [23]. The modified Boos score $(0-29)$ is used to determine the degree of histologic canine IVD degeneration and includes the following subcriteria: morphology of the AF, chondrocyte metaplasia in the $\mathrm{AF}$, tear and cleft formation (in NP and AF), chondrocyte proliferation in the NP, presence of NCs in the NP, PSR/AB matrix staining of the NP, EP morphology, new bone formation, and subchondral bone sclerosis [23]. Immunohistochemistry for collagen type I, II, and $\mathrm{X}$ [5] and COX-2 [55] were performed as described previously. For COX-2, (positively stained) cell numbers in four randomly selected NP areas per IVD section were manually counted (Adobe Photoshop CC). The mean percentage of immunopositive cells was calculated.

\section{Gene expression profiling and biochemical analysis}

Details on RNA isolation, cDNA synthesis, and RT-qPCR are provided in Supplementary File 5E. To determine the GAG and DNA content, the NP and AF samples were homogenized in complete lysis buffer using TissueLyser II (Qiagen) for 4 minutes at $20 \mathrm{~Hz}$. PGE2 levels were determined in the supernatant using a colorimetric competitive enzyme immunoassay kit (PGE2 high sensitivity EIA kit, ENZO Life Sciences) as described previously [55]. The DNA and GAG content were measured in papain-digested supernatant and pellet as described previously [52]. A hydroxyproline assay [56] was used to determine the samples collagen content as described previously [52]. Briefly, samples were freeze-dried overnight, hydrolyzed in $4 \mathrm{M} \mathrm{NaOH}$ at $108^{\circ} \mathrm{C}$ overnight, centrifuged ( 15 seconds, $14,000 \mathrm{~g}$ ) and stored at $-20^{\circ} \mathrm{C}$. Prior to measurement, samples were centrifuged (15 seconds, 14,000 g), chloramine $\mathrm{T}$ reagent (2426, Merck) was added, and samples were shaken for 20 minutes $(170 \mathrm{rpm})$. Freshly prepared dimethylaminobenzaldehyde (3058, Merck) was added, samples were incubated for 20 minutes at $60^{\circ} \mathrm{C}$, the absorbance was read $(570 \mathrm{~nm})$, and the collagen content was calculated by multiplying the hydroxyproline content with factor 7.5 [52]. MSC fate was determined by SRY:GAPDH PCR on genomic DNA isolated from papain-digested sample as described previously [57]. The detection limit of this assay was $250 \mathrm{MSCs} / \mu \mathrm{L}$ buffer (determined by a dilution series of positive control sample), which equals 25,000 MSCs/Beagle NP.

\section{Statistical analyses}

Statistical analyses were performed using IBM SPSS Statistics 24 and R studio. The Shapiro Wilks test was used to examine the data for normal distribution. Nonparametric data were converted to normally distributed data (log transformation) when possible. Two-sided testing was performed. To correct for multiple comparisons, Benjamini \& Hochberg False Discovery Rate post-hoc tests were performed. For in vitro experiments, normally distributed data were examined using general linear regression models based on ANOVAs, whereas nonnormally distributed data were subjected to Kruskal Wallis and Mann-Whitney $U$ tests. For in vivo experiments, a randomized block design ANOVA was used for normally distributed data (DNA, GAG, collagen, PGE2 content). For DHI, quantitative T1 $\rho$ and T2 mapping, and RTqPCR data, Cox proportional hazard tests were performed (random effect: donor). For Boos, Thompson, and 
Pfirrmann data analysis, Mann-Whitney Wilcoxon tests were performed. Because of the small in vivo sample size, for all comparisons with $0.05 \geq p \leq 0.20$, effect sizes (ES; Hedge's g for normally distributed data, Cliff's delta for non-parametric data) were determined and classified as described previously $[58,59]$. $p$-values $<0.05$ were considered significant. Medium-very large effect sizes (Hedge's g $\geq 0.5$, Cliff's delta $\geq 0.28$ ) were considered relevant.

\section{CONCLUSIONS}

The present study demonstrates that NCM exerted regenerative effects on canine MSCs and on canine and human CLCs from degenerated IVDs in vitro as well as on canine IVDs in vivo. In vivo, NCM mainly exerted effects on moderately degenerated IVDs; a repeated intradiscal NCM injection exerted beneficial effects on macroscopic, radiologic, biochemical, and histological level and inhibited inflammation. This is the first study that shows that intradiscally injected NCM could potentially be a promising treatment for human and canine IVD disease, by harnessing the $\mathrm{NC}$ regenerative and anti-inflammatory potential, and circumventing the challenging identification of bioactive NC-secreted factors. This approach should be feasible in light of the wide clinical application of demineralized bone matrix within the bone regeneration field. Future studies should focus on removal of nucleic acid from NCM and the mechanism of NCM-mediated regeneration.

\section{Abbreviations}

ACAN: aggrecan; ADAMTS5: a disintegrin and metalloproteinase with thrombospondin motifs 5; AF: annulus fibrosus; AGE: advanced glycation end products; BAX: B-cell lymphoma 2 associated X; BCL2: B-cell lymphoma 2; CASP3: caspase 3; CCND1: cyclin D1; CLC: chondrocyte-like cell; COL1A1: collagen type 1A1; COL2A1: collagen type 2A1; COL10A1: collagen type 10A1; COX-2: cyclo-oxygenase-2; CT: computer tomography; DHI: disc height index; DMB: demineralized bone matrix; ECM: extracellular matrix; EP: end plate; ES: effect size; GAG: glycosaminoglycan; IL-1 $\beta$ : interleukin $1 \beta$; IVD: intervertebral disc; LBP: low back pain; MC: modic change; MMP13: martix metalloproteinase 13; MRI: magnetic resonance imaging; MSC: mesenchymal stromal cell; NC: notochordal cell; NCM: notochordal cell-derived matrix; NP: nucleus pulposus; NX: partial nucleus pulposus removal; PAI1: plasminogen activator inhibitor type 1; PGE2: prostaglandin E2; SOX9: sexdetermining region of Y-box9; SRY: sex-determining region of Y; TGF- $\beta$ : transforming growth factor- $\beta$; TIMP1: tissue inhibitor of metalloproteinases; TNF $\alpha$ : tumor necrosis factor $\alpha$.

\section{Author contributions}

The manuscript has been read and approved by ALL named authors. There are no other persons who satisfied the criteria for authorship. Each author has contributed to a minimum of two of the four major parts of the submitted work and there are no "Gift Authorships". Given the extent of the study, 12 authors have been listed. They contributed as follows: FCB collected material, performed most of the experiments, mined and analyzed the data, participated in the design of the study, and drafted the manuscript. ART, MT, WAMJ, SAHV, MB assisted in collection of material, performance of experiments and mining the data. LBC provided human CLCs. KB provided the hydrogels. $\mathrm{KI}$, BPM, MAT contributed to the study design and data analysis. MAT, BPM, KI conceived the study and coordinated the process.

\section{ACKNOWLEDGMENTS}

The authors would like to thank Simon Mastbergen and Katja Coeleveld for help with the ${ }^{35} \mathrm{SO}_{4}{ }^{2-}$ incorporation assay, Saskia Plomp, Amber van Heezen and Pascal Kamphuis for the help with execution of experiments, Anita Krouwels and Imke Janssen for supplying human CLCs, and Nico Attevelt, Jeroen van Ark and Helma Averzaat (Animal Facilities of Utrecht University) for support during this study.

\section{CONFLICTS OF INTEREST}

None.

\section{FUNDING}

This work was funded by an AOSpine International (SRN2011_11) and supported by long last funding from the Dutch Arthritis Foundation (LLP22 and LLP12).

\section{REFERENCES}

1. Katz JN. Lumbar disc disorders and low-back pain: socioeconomic factors and consequences. The Journal of bone and joint surgery. American volume. 2006; 88:21-24.

2. Freemont AJ. The cellular pathobiology of the degenerate intervertebral disc and discogenic back pain. Rheumatology (Oxford, England). 2009; 48:5-10.

3. Bergknut N, Smolders LA, Grinwis GC, Hagman R, Lagerstedt AS, Hazewinkel HA, Tryfonidou MA, Meij BP. Intervertebral disc degeneration in the dog. Part 1: Anatomy and physiology of the intervertebral disc and characteristics of intervertebral disc degeneration. Veterinary journal (London, England : 1997). 2013; 195:282-291.

4. Hunter CJ, Matyas JR, Duncan NA. Cytomorphology of notochordal and chondrocytic cells from the nucleus 
pulposus: a species comparison. Journal of anatomy. 2004; 205:357-362.

5. Bach FC, de Vries SA, Krouwels A, Creemers LB, Ito K, Meij BP, Tryfonidou MA. The species-specific regenerative effects of notochordal cell-conditioned medium on chondrocyte-like cells derived from degenerated human intervertebral discs. European cells \& materials. 2015; 30:132-47.

6. Abbott RD, Purmessur D, Monsey RD, Iatridis JC. Regenerative potential of TGFbeta3 + Dex and notochordal cell conditioned media on degenerated human intervertebral disc cells. Journal of orthopaedic research. 2012; 30:482-488.

7. Potier E, de Vries S, van Doeselaar M, Ito K. Potential application of notochordal cells for intervertebral disc regeneration: an in vitro assessment. European cells \& materials. 2014; 28:68-81.

8. Korecki CL, Taboas JM, Tuan RS, Iatridis JC. Notochordal cell conditioned medium stimulates mesenchymal stem cell differentiation toward a young nucleus pulposus phenotype. Stem cell research \& therapy. 2010; 1:18.

9. Purmessur D, Schek RM, Abbott RD, Ballif BA, Godburn KE, Iatridis JC. Notochordal conditioned media from tissue increases proteoglycan accumulation and promotes a healthy nucleus pulposus phenotype in human mesenchymal stem cells. Arthritis research \& therapy. 2011; 13:R81.

10. de Vries SA, Potier E, van Doeselaar M, Meij BP, Tryfonidou MA, Ito K. Conditioned medium derived from notochordal cell-rich nucleus pulposus tissue stimulates matrix production by canine nucleus pulposus cells and bone marrow-derived stromal cells. Tissue engineering. Part A. $2015 ; 21: 1077-1084$.

11. de Vries SA, van Doeselaar M, Meij BP, Tryfonidou MA, Ito K. The Stimulatory Effect of Notochordal CellConditioned Medium in a Nucleus Pulposus Explant Culture. Tissue engineering. Part A. 2016; 22:103-110.

12. Matta A, Karim MZ, Isenman DE, Erwin WM. Molecular Therapy for Degenerative Disc Disease: Clues from Secretome Analysis of the Notochordal Cell-Rich Nucleus Pulposus. Scientific reports. 2017; 7:45623.

13. Bach FC, de Vries SA, Riemers FM, Boere J, van Heel FW, van Doeselaar M, Goerdaya SS, Nikkels PG, Benz K, Creemers LB, Maarten Altelaar AF, Meij BP, Ito K, et al. Soluble and pelletable factors in porcine, canine and human notochordal cell-conditioned medium: implications for IVD regeneration. European cells \& materials. 2016; 32:163-180.

14. Bach F, Libregts S, Creemers L, Meij B, Ito K, Wauben M, Tryfonidou M. Notochordal-cell derived extracellular vesicles exert regenerative effects on canine and human nucleus pulposus cells. Oncotarget. 2017; 8:88845-88856. https://doi.org/10.18632/oncotarget.21483.

15. Gruskin E, Doll BA, Futrell FW, Schmitz JP, Hollinger JO. Demineralized bone matrix in bone repair: history and use. Advanced Drug Delivery Reviews. 2012; 64:1063-1077.
16. Sakai D, Nakai T, Mochida J, Alini M, Grad S. Differential phenotype of intervertebral disc cells: microarray and immunohistochemical analysis of canine nucleus pulposus and anulus fibrosus. Spine. 2009; 34:1448-1456.

17. Wu T, Song HX, Dong Y, Li JH. Cell-Based Therapies for lumbar discogenic low back pain - Systematic Review and Single Arm Meta-Analysis. Spine. 2018; 43:49-57.

18. Bergknut N, Rutges JP, Kranenburg HJ, Smolders LA, Hagman R, Smidt HJ, Lagerstedt AS, Penning LC, Voorhout G, Hazewinkel HA, Grinwis GC, Creemers LB, Meij BP, et al. The dog as an animal model for intervertebral disc degeneration?. Spine. 2012; 37:351-358.

19. Dominici M, Le Blanc K, Mueller I, Slaper-Cortenbach I, Marini F, Krause D, Deans R, Keating A, Prockop D, Horwitz E. Minimal criteria for defining multipotent mesenchymal stromal cells. The International Society for Cellular Therapy position statement. Cytotherapy. 2006; 8:315-317.

20. Screven R, Kenyon E, Myers MJ, Yancy HF, Skasko M, Boxer L, Bigley EC 3rd, Borjesson DL, Zhu M. Immunophenotype and gene expression profile of mesenchymal stem cells derived from canine adipose tissue and bone marrow. Veterinary immunology and immunopathology. 2014; 161:21-31.

21. Bergknut N, Grinwis G, Pickee E, Auriemma E, Lagerstedt AS, Hagman R, Hazewinkel HA, Meij BP. Reliability of macroscopic grading of intervertebral disk degeneration in dogs by use of the Thompson system and comparison with low-field magnetic resonance imaging findings. American Journal of Veterinary Research. 2011; 72:899-904.

22. Bergknut N, Auriemma E, Wijsman S, Voorhout G, Hagman R, Lagerstedt AS, Hazewinkel HA, Meij BP. Evaluation of intervertebral disk degeneration in chondrodystrophic and nonchondrodystrophic dogs by use of Pfirrmann grading of images obtained with low-field magnetic resonance imaging. American Journal of Veterinary Research. 2011; 72:893-898.

23. Bergknut N, Meij BP, Hagman R, de Nies KS, Rutges JP, Smolders LA, Creemers LB, Lagerstedt AS, Hazewinkel HA, Grinwis GC. Intervertebral disc disease in dogs - part 1: a new histological grading scheme for classification of intervertebral disc degeneration in dogs. Veterinary journal (London, England : 1997). 2013; 195:156-163.

24. Ishida K, Acharya C, Christiansen BA, Yik JH, DiCesare PE, Haudenschild DR. Cartilage oligomeric matrix protein enhances osteogenesis by directly binding and activating bone morphogenetic protein-2. Bone. 2013; 55:23-35.

25. Ayerst BI, Merry CLR, Day AJ. The Good the Bad and the Ugly of Glycosaminoglycans in Tissue Engineering Applications. Pharmaceuticals (Basel, Switzerland). 2017; 10: 10.3390/ph10020054.

26. Vadala G, Sowa G, Hubert M, Gilbertson LG, Denaro V, Kang JD. Mesenchymal stem cells injection in degenerated intervertebral disc: cell leakage may induce osteophyte 
formation. Journal of tissue engineering and regenerative medicine. 2012; 6:348-355.

27. Ganey T, Hutton WC, Moseley T, Hedrick M, Meisel HJ. Intervertebral disc repair using adipose tissue-derived stem and regenerative cells: experiments in a canine model. Spine. 2009; 34:2297-2304.

28. Hiyama A, Mochida J, Iwashina T, Omi H, Watanabe T, Serigano K, Tamura F, Sakai D. Transplantation of mesenchymal stem cells in a canine disc degeneration model. Journal of orthopaedic research. 2008; 26:589-600.

29. Serigano K, Sakai D, Hiyama A, Tamura F, Tanaka M, Mochida J. Effect of cell number on mesenchymal stem cell transplantation in a canine disc degeneration model. Journal of orthopaedic research. 2010; 28:1267-1275.

30. Phinney DG. Functional heterogeneity of mesenchymal stem cells: implications for cell therapy. Journal of cellular biochemistry. 2012; 113:2806-2812.

31. Illien-Junger S, Sedaghatpour DD, Laudier DM, Hecht AC, Qureshi SA, Iatridis JC. Development of a bovine decellularized extracellular matrix-biomaterial for nucleus pulposus regeneration. Journal of orthopaedic research. 2016; 34:876-888.

32. Rutges JP, Duit RA, Kummer JA, Oner FC, van Rijen $\mathrm{MH}$, Verbout AJ, Castelein RM, Dhert WJ, Creemers LB. Hypertrophic differentiation and calcification during intervertebral disc degeneration. Osteoarthritis and cartilage/OARS, Osteoarthritis Research Society. 2010; 18:1487-1495.

33. Eyre DR, Muir H. Quantitative analysis of types I and II collagens in human intervertebral discs at various ages. Biochimica et biophysica acta. 1977; 492:29-42.

34. Smolders LA, Kingma I, Bergknut N, van der Veen AJ, Dhert WJ, Hazewinkel HA, van Dieen JH, Meij BP. Biomechanical assessment of the effects of decompressive surgery in non-chondrodystrophic and chondrodystrophic canine multisegmented lumbar spines. European spine journal. 2012; 21:1692-1699.

35. Johannessen W, Auerbach JD, Wheaton AJ, Kurji A, Borthakur A, Reddy R, Elliott DM. Assessment of human disc degeneration and proteoglycan content using T1rhoweighted magnetic resonance imaging. Spine. 2006; 31:1253-1257.

36. Link TM, Stahl R, Woertler K. Cartilage imaging: motivation, techniques, current and future significance. European radiology. 2007; 17:1135-1146.

37. Sivan SS, Tsitron E, Wachtel E, Roughley P, Sakkee N, van der Ham F, Degroot J, Maroudas A. Age-related accumulation of pentosidine in aggrecan and collagen from normal and degenerate human intervertebral discs. The Biochemical journal. 2006; 399:29-35.
38. Urban J, Roberts S, Ralphs J. The nucleus of the intervertebral disc from development to degeneration. Am Zool. 2000; 40:53-61.

39. Jazini E, Sharan AD, Morse LJ, Dyke JP, Aronowitz EB, Chen LK, Tang SY. Alterations in T2 relaxation magnetic resonance imaging of the ovine intervertebral disc due to nonenzymatic glycation. Spine. 2012; 37:E209-15.

40. Linka K, Itskov M, Truhn D, Nebelung S, Thuring J. T2 MR imaging vs. computational modeling of human articular cartilage tissue functionality. Journal of the mechanical behavior of biomedical materials. 2017; 74:477-487.

41. Peeters M, Detiger SE, Karfeld-Sulzer LS, Smit TH, Yayon A, Weber FE, Helder MN. BMP-2 and BMP-2/7 Heterodimers Conjugated to a Fibrin/Hyaluronic Acid Hydrogel in a Large Animal Model of Mild Intervertebral Disc Degeneration. BioResearch open access. 2015; 4:398-406.

42. Illien-Junger S, Grosjean F, Laudier DM, Vlassara H, Striker GE, Iatridis JC. Combined anti-inflammatory and anti-AGE drug treatments have a protective effect on intervertebral discs in mice with diabetes. PLoS One. 2013; 8:e64302.

43. Kim JH, Moon HJ, Lee JH, Kim JH, Kwon TH, Park YK. Rabbit notochordal cells modulate the expression of inflammatory mediators by human annulus fibrosus cells cocultured with activated macrophage-like THP-1 cells. Spine. 2012; 37:1856-1864.

44. Mwale F, Masuda K, Pichika R, Epure LM, Yoshikawa T, Hemmad A, Roughley PJ, Antoniou J. The efficacy of Link N as a mediator of repair in a rabbit model of intervertebral disc degeneration. Arthritis research \& therapy. 2011; 13:R120.

45. Malagola E, Teunissen M, van der Laan LJ, Verstegen MM, Schotanus BA, van Steenbeek FG, Penning LC, van Wolferen ME, Tryfonidou MA, Spee B. Characterization and Comparison of Canine Multipotent Stromal Cells Derived from Liver and Bone Marrow. Stem cells and development. 2016; 25:139-150.

46. Farndale RW, Sayers CA, Barrett AJ. A direct spectrophotometric microassay for sulfated glycosaminoglycans in cartilage cultures. Connective tissue research. 1982; 9:247-248.

47. Lafeber FP, Vander Kraan PM, Van Roy JL, Huber-Bruning O, Bijlsma JW. Articular cartilage explant culture; an appropriate in vitro system to compare osteoarthritic and normal human cartilage. Connective tissue research. 1993; 29:287-299.

48. Benz K, Stippich C, Osswald C, Gaissmaier C, Lembert N, Badke A, Steck E, Aicher WK, Mollenhauer JA. Rheological and biological properties of a hydrogel support for cells intended for intervertebral disc repair. BMC musculoskeletal disorders. 2012; 13:54-2474-13-54. 
49. Gruber HE, Ingram J, Hanley EN Jr. An improved staining method for intervertebral disc tissue. Biotechnic \& histochemistry. 2002; 77:81-83.

50. Lv FJ, Tuan RS, Cheung KM, Leung VY. Concise review: the surface markers and identity of human mesenchymal stem cells. Stem cells (Dayton, Ohio). 2014; 32:1408-1419.

51. Robey P. "Mesenchymal stem cells": fact or fiction, and implications in their therapeutic use. F1000Research. 2017; F1000 Faculty Rev-524. https://doi.org/10.12688/ f1000research.10955.1.

52. Willems $\mathrm{N}$, Bach FC, Plomp $\mathrm{SG}$, van Rijen $\mathrm{MH}$, Wolfswinkel J, Grinwis GC, Bos C, Strijkers GJ, Dhert WJ, Meij BP, Creemers LB, Tryfonidou MA. Intradiscal application of rhBMP-7 does not induce regeneration in a canine model of spontaneous intervertebral disc degeneration. Arthritis research \& therapy. 2015; 17:137-015-0625-2.

53. Landis JR, Koch GG. The measurement of observer agreement for categorical data. Biometrics. 1977; 33:159-174.

54. Masuda K, Imai Y, Okuma M, Muehleman C, Nakagawa K, Akeda K, Thonar E, Andersson G, An HS. Osteogenic protein-1 injection into a degenerated disc induces the restoration of disc height and structural changes in the rabbit anular puncture model. Spine. 2006; 31:742-754.

55. Willems N, Tellegen AR, Bergknut N, Creemers LB, Wolfswinkel J, Freudigmann C, Benz K, Grinwis GC, Tryfonidou MA, Meij BP. Inflammatory profiles in canine intervertebral disc degeneration. BMC veterinary research. 2016; 12:10-016-0635-6.

56. Neuman RE, Lo MA. The determination of hydroxyproline. The Journal of biological chemistry. 1950; 184:299-306.

57. Bach FC, Miranda-Bedate A, van Heel FW, Riemers FM, Muller MC, Creemers LB, Ito K, Benz K, Meij BP, Tryfonidou MA. Bone Morphogenetic Protein-2, But Not Mesenchymal Stromal Cells, Exert Regenerative Effects on Canine and Human Nucleus Pulposus Cells. Tissue engineering. Part A. 2017; 23:233-242.

58. Sawilowsky S. New effect size rules of thumb. Journal of Modern Applied Statistical Methods. 2009; 8:597-599.

59. Cliff N. Dominance statistics: Ordinal analyses to answer ordinal questions. Psychological Bulletin. 1993; 114:494-509. 